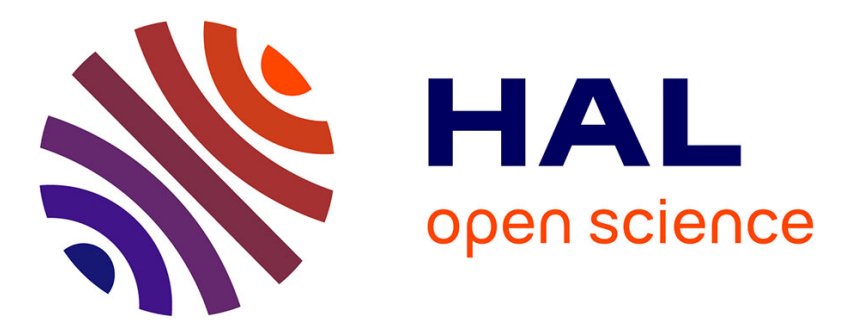

\title{
pH-Controlled Self-Assembled Fibrillar Network Hydrogels: Evidence of Kinetic Control of the Mechanical Properties
}

Ghazi Ben Messaoud, Patrick Le Griel, Daniel Hermida-Merino, Sophie L. K. W. Roelants, Wim Soetaert, Christian Victor Stevens, Niki Baccile

\section{To cite this version:}

Ghazi Ben Messaoud, Patrick Le Griel, Daniel Hermida-Merino, Sophie L. K. W. Roelants, Wim Soetaert, et al.. pH-Controlled Self-Assembled Fibrillar Network Hydrogels: Evidence of Kinetic Control of the Mechanical Properties. Chemistry of Materials, 2019, 31 (13), pp.4817-4830. 10.1021/acs.chemmater.9b01230 . hal-02160875

\section{HAL Id: hal-02160875 \\ https://hal.sorbonne-universite.fr/hal-02160875}

Submitted on 20 Jun 2019

HAL is a multi-disciplinary open access archive for the deposit and dissemination of scientific research documents, whether they are published or not. The documents may come from teaching and research institutions in France or abroad, or from public or private research centers.
L'archive ouverte pluridisciplinaire HAL, est destinée au dépôt et à la diffusion de documents scientifiques de niveau recherche, publiés ou non, émanant des établissements d'enseignement et de recherche français ou étrangers, des laboratoires publics ou privés. 
2 pH-controlled self-assembled fibrillar network (SAFiN) hydrogels:

3 evidence of a kinetic control of the mechanical properties

4 Ghazi Ben Messaoud, ${ }^{\mathrm{a}, \dagger}$ Patrick Le Griel, ${ }^{\mathrm{a}}$ Daniel Hermida-Merino, ${ }^{\mathrm{b}}$ Sophie L. K. W.

5 Roelants, ${ }^{\mathrm{c}, \mathrm{d}}$ Wim Soetaert, ${ }^{\mathrm{c}}$ Christian Victor Stevens, ${ }^{\mathrm{e}}$ Niki Baccile ${ }^{\mathrm{a}, *}$

6

7

8

9

10

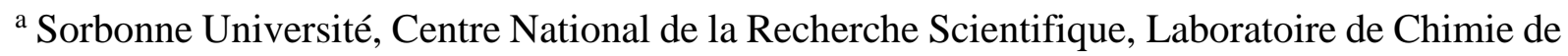
la Matière Condensée de Paris, LCMCP, F-75005 Paris, France

$\dagger$ Current address: DWI- Leibniz Institute for Interactive Materials, Forckenbeckstrasse 50, 52056 Aachen, Germany

${ }^{\mathrm{b}}$ Netherlands Organisation for Scientific Research (NWO), DUBBLE@ESRF BP CS40220, 38043 Grenoble, France

${ }^{\mathrm{c}}$ Ghent University, Centre for Industrial Biotechnology and Biocatalysis (InBio.be), Coupure Links 653, Ghent, Oost-Vlaanderen, BE 9000

${ }^{\mathrm{d}}$ Bio Base Europe Pilot Plant, Rodenhuizekaai 1, Ghent, Oost-Vlaanderen, BE 9000

${ }^{\mathrm{e}}$ SynBioC, Department of Green Chemistry and Technology, Ghent University, Coupure Links 653, 9000 Ghent, Belgium.

\section{* Corresponding author:}

Dr. Niki Baccile

E-mail address: niki.baccile@upmc.fr

Phone: 0033144275677 


\section{Abstract}

Control of the nucleation and growth process in self-assembled fibrillary networks (SAFiN) with the goal of preparing physical hydrogels from low molecular weight gelators (LMWG) is well-established but mainly for temperature-driven hydrogelators. In the presence of other stimuli, like $\mathrm{pH}$, the fundamental knowledge behind gel formation still lacks. In particular, whether $\mathrm{pH}$ affects nucleation and growth of the fibers and how this aspect could be related to the stability of the hydrogel is still matter of debate. In this work, we establish a precise relationship between the $\mathrm{pH}$ change rate during the micelle-to-fiber transition, observed for stearic acid sophorolipids - a bolaform microbial glycolipid - and supersaturation. We show that tough SAFiN hydrogels are obtained for slow $\mathrm{pH}$ change rates, when supersaturation is low, while weak gels, or even phase separation through powder precipitation, are obtained upon fast $\mathrm{pH}$ change. Interestingly, these results are independent of the $\mathrm{pH}$ change method, may it be through manual variation using $\mathrm{HCl}$, or by using the internal hydrolysis of glucono- $\delta$-lactone (GDL), the latter being currently acknowledged as a unique way to systematically obtain tough gel through internal $\mathrm{pH}$ change.

\section{Introduction}

The development of soft stimuli-responsive materials is a topic that has gained much attention in the past decades for the applications in many fields including tissue engineering, cosmetics, food and environmental science ${ }^{1-8}$ and in relationship to the most recent materials' processing techniques, like $3 \mathrm{D}^{6}$ and $4 \mathrm{D}$ printing. ${ }^{9}$ In this field, low molecular weight gelators (LMWG) ${ }^{10,11}$ small compounds commonly forming self-assembled fibrillary network (SAFiN) hydro- or organogels, attract a large interest for their potentially infinite possibilities in terms of the (molecular) function - (gel) property. The gelation is generally driven by weak interactions and can be triggered by numerous stimuli like temperature, ${ }^{12} \mathrm{pH},{ }^{13}$ salt $^{14}$ or enzymes. ${ }^{15}$ In this class of materials, fluorenyl-9-methoxycarbonyl (Fmoc) amino acid derivatives are one of the most popular class of LMWG but peptides, peptide amphiphiles and glycolipids ${ }^{16-20}$ are also largely explored.

Temperature-driven SAFiN hydro- and organogels are by far the most common systems benefitting of the largest knowledge. Their mechanisms of formation and relationship between the gel mechanical properties and fiber nucleation/growth phenomena are well-understood. Supersaturation, driven by large temperature variations between the sol and gel phases, is responsible for high degrees of fiber branching, leading to gels with poor mechanical properties. ${ }^{21-24}$ However, when it comes to the preparation of homogenous SAFiN hydrogels 
triggered by $\mathrm{pH}$ as external stimulus, control of $\mathrm{pH}$ variation and of mechanical properties is still challenging. Several approaches, like generation of carboxylic acids during anhydrides hydrolysis ${ }^{25}$ or UV irradiation of a photoacid generator ${ }^{26}$ were developed as better alternatives to an obvious manual addition of the acid. However, since a decade, it is commonly acknowledged that use of glucono- $\delta$-lactone (GDL, Figure 1b) is a straightforward, economic and smart approach: in situ release of gluconic acid during the hydrolysis of GDL promotes the formation of homogeneous SAFiN hydrogels. ${ }^{2,16,27,28}$ However, whichever the method of acidification, the mechanisms of $\mathrm{pH}$ variation in relationship to the mechanical strength of the gel are not fully understood. This is particularly true for hydrogels prepared by manual $\mathrm{pH}$ change and of which the reported variations in terms of mechanical properties are also ascribed to the differences in shear induced by mixing during gel formation. ${ }^{29}$ Even for GDL, such a relationship is not obvious and it is generally assumed that the final $\mathrm{pH}$ is practically the main parameter that controls the mechanical properties of the hydrogels. ${ }^{2,30,31}$

Recently, we have described the $\mathrm{pH}$-induced fibrillation of the stearic derivative of acidic sophorolipids (SLC18:0, Figure 1a). ${ }^{32}$ Sophorolipids are the most common, abundant and commercially-available microbial glycolipid biosurfactant in the literature, ${ }^{33,34}$ with interesting self-assembly properties ${ }^{35-37}$ and a wide range of applications for their low environmental impact, low cytotoxicty and good antimicrobial properties. ${ }^{33,34,38}$ SLC18:0 is known to undergo a $\mathrm{pH}$-driven micelle-to-fiber (twisted ribbon) phase transition at $\mathrm{pH} \sim 7.4$ (Figure 1a), below which this compound forms a SAFiN, although the formation of a hydrogel was never reported. To the best of our knowledge, in the broader field of glycolipid biosurfactants, only cellobioselipids and non-acidic symmetrical sophorolipids were shown to have gelling properties. ${ }^{39-41}$

If this compound could be expected to form a SAFiN hydrogel, which we show as the first result of this work, we also report an unprecedented role of the kinetics of $\mathrm{pH}$ variation to control the hydrogel homogeneity and to improve its mechanical properties. In contrast to the abundant literature on pH-driven LMWG hydrogels (often composed of Fmoc-derivatives), we show that both heterogeneous (through external $\mathrm{HCl}$ addition) and homogeneous (through internal GDL hydrolysis) acidification can induce the formation of homogeneous SAFiN hydrogels with comparable mechanical properties. We show that fine tuning of the acidification rate, using either $\mathrm{HCl}$ or GDL, controls the formation of a strong (homogeneous SAFiN), weak gel or even no gel at all, due to the formation of spherulites. By combining rheology, multiscale (from $\mathrm{nm}$ to $\mathrm{mm}$ ) structural analysis and exploring the $\mathrm{pH}$-induced sol-gel transition by nuclear magnetic resonance (NMR) in solution, we propose that the formation of SLC18:0 
93 hydrogels is not driven by the final $\mathrm{pH}$ but it is a diffusion-limited process. Under these 94 circumstances, the method of acidification (external or internal) is not as important as initially imagined, because supersaturation plays a much more crucial role in the nucleation and growth mechanisms of the fibers during $\mathrm{pH}$ variation, in analogy to what is known in temperaturedriven LMWG SAFiN. ${ }^{21,42-44}$ Slow $\mathrm{pH}$ variation kinetics promote homogeneous fibrillation and tough hydrogels while fast kinetics induce spherulite formation and phase separation.

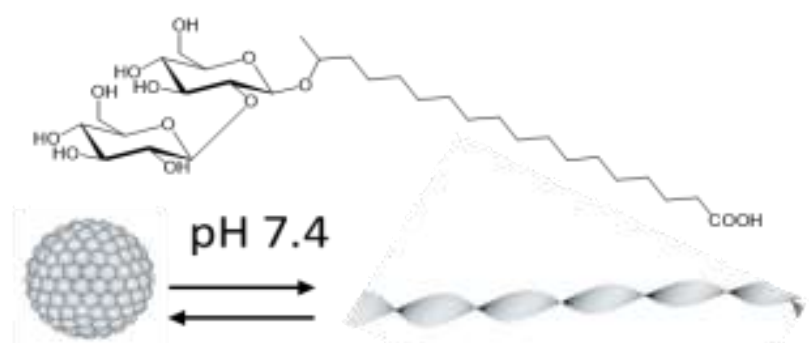

a)

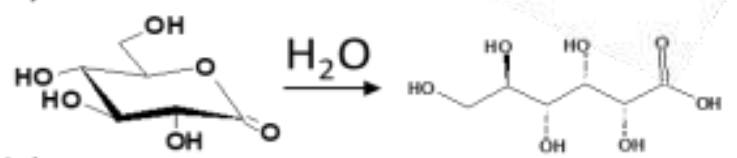

b)

Figure 1 - a) Chemical structure of SLC18:0 microbial glycolipid and its pH-driven assembly from micelles to fibers and b) hydrolysis of glucono- $\delta$-lactone (GDL) to gluconic acid in water. 


\section{Experimental Section}

Chemicals. SLC18:0 $\left(\mathrm{M}_{\mathrm{w}}=624.8 \mathrm{~g} \cdot \mathrm{mol}^{-1}\right)$ was obtained from SLC18:1 (Soliance, now Givaudan Active Beauty, France). The monounsaturated SLC18:1 was first hydrolyzed in an alkaline medium and the $\mathrm{pH}$ is then adjusted to $\sim 4.5$ to obtain the deacetylated open acidic form and finally recovered using method 1 as reported previously. ${ }^{45}$ The fully saturated SLC18:0 was then obtained by a chemical modification step described elsewhere. ${ }^{32}$ Glucono- $\delta$-lactone $\left(\mathrm{GDL}, \mathrm{Mw}=178.1 \mathrm{~g} \cdot \mathrm{mol}^{-1}\right)$ was purchased from Sigma Aldrich. $5 \mathrm{M} \mathrm{NaOH}$ and $\mathrm{HCl}$ stock solutions were respectively prepared by the dissolution of an appropriate amount of solid sodium hydroxide pellets (Sigma Aldrich) in water and by diluting $37 \mathrm{w} \%$ hydrochloric acid (Sigma Aldrich) in water. All solutions were prepared with Milli-Q-grade water.

Preparation of the hydrogels. The general method to prepare the hydrogels consists in dispersing a given amount of SLC18:0 (in wt\%) in water at the desired concentration, followed by sonication during 1-2 minutes, to break up the aggregated powder. The $\mathrm{pH}$ of the solution is increased to $\mathrm{pH} \sim 11$ under gentle magnetic stirring with few $\mu \mathrm{L}$ of $5 \mathrm{M} \mathrm{NaOH}$ (generally between $5 \mu \mathrm{L}$ and $20 \mu \mathrm{L}$, according to the sample concentration, for a typical volume of $1 \mathrm{~mL}$ ). The solution, turbid at the equilibrium $\mathrm{pH}$, becomes mostly clear at basic $\mathrm{pH}$, as discussed in previous work, ${ }^{32}$ although slight turbidity can occur above $\mathrm{pH} 11$ due to the formation of platelets. ${ }^{46}$ Hydrogels are then obtained by acidification of the basic solution. However, the method to decrease the $\mathrm{pH}$ is critical for the hydrogel stability and properties. We present three methods of acidification, of which two of them are classical in the literature, while the third was specifically developed in this work.

1) Manual acidification using $\mathrm{HCl}$. Manual acidification is a simple and classical approach to decrease the $\mathrm{pH}$. Despite its optimization to this specific system, one should be careful to use it to obtain SLC18:0 hydrogels, because it lacks of precision and reproducibility. Briefly, solutions of $1 \mathrm{M}$ and $0.5 \mathrm{M}$ of $\mathrm{HCl}$ are used to manually acidify the SLC18:0 solution (values here are intended for a typical $1 \mathrm{~mL}$ solution). $\mathrm{pH}$ can be varied rapidly using $1 \mathrm{M} \mathrm{HCl}$ solution until $\mathrm{pH} \sim 7.4$. Then $2 \mu \mathrm{L}$ of a $0.5 \mathrm{M} \mathrm{HCl}$ (for $\mathrm{SL} \leq 2.5 \mathrm{wt} \%$ ) or a $1 \mathrm{M} \mathrm{HCl}$ solution (for SL > $2.5 \mathrm{wt} \%)$ are added dropwise under gentle stirring ( $100 \mathrm{rpm})$ using a magnetic bar. If small aggregates appear in solution, the sample must be sonicated between each added aliquot until the aggregates dissolve. The solution becomes then more and more turbid, but homogeneous. The stirring rate of the sample should be increased (> $300 \mathrm{rpm}$ ) due to the rise of the solution viscosity. Under these conditions, one can keep adding $\mathrm{HCl}$ until the desired final $\mathrm{pH}$ is reached (tough gels are generally obtained at $\mathrm{pH} \sim 6$ ). If these steps are not performed 
correctly, one obtains a biphasic system composed of a precipitate and a slightly turbid aqueous phase at already $\mathrm{pH} \sim 7$ and $\mathrm{pH}$ should be increased again to solubilize the sample and start the acidification step again. Regeneration of the sample generates larger amounts of salt (here, $\mathrm{NaCl}$ ) and which may interfere with gel formation. However, salt concentrations up to at least $200 \mathrm{mM}$ do not perturb gel formation. We discuss this point in the last section of the manuscript. To increase the chances to reach the gel phase, we suggest to add a lag time of $5 \mathrm{~min}$ to $10 \mathrm{~min}$ between each addition of $\mathrm{HCl}$ aliquots in the $\mathrm{pH}$ region between 7.4 and 6.5, when the micelle to fiber transition occurs. In a standard successful experiment, the total amount of $\mathrm{HCl} 1 \mathrm{M}$ added should not increase $50 \mu \mathrm{L}$ for a $1 \mathrm{~mL}$ solution at $5 \mathrm{wt} \%$, that is final concentration of about $50 \mathrm{mM} \mathrm{HCl}$. The final dilution factor, after taking into account the added volume of $\mathrm{NaOH}$ and $\mathrm{HCl}$ generally does not not exceed 1.03 1.04. Using $\mathrm{HCl}$ solution of molarity above $1 \mathrm{M}$ is not recommended due to the sharper $\mathrm{pH}$ jumps, which promote the formation of a precipitate.

2) Use of GDL. In-situ hydrolysis of GDL is known to yield reproducible, stable and tough hydrogels in low molecular weight gelators. This method was adapted to this system as follows. A given amount of GDL is weighted in a vial, to which the SLC18:0 solution at basic $\mathrm{pH}$ is added. Mixing is immediately achieved by vortexing for approximately 20 - 30 seconds and the sample is left at rest (no stirring is applied) with gelation taking place over few hours. The amounts are approximately 1:0.63 $( \pm 15 \%)=$ SLC18:0:GDL molar ratio for a SLC18:0 solution at $\mathrm{pH} \sim 11$, and one can also follow the data in Table 1 for convenience. These values are indicative and we suggest the reader to optimize the amount of GDL on his/her own system. In fact, the error in the amount of GDL strongly depends on the amount of base introduced in the solution, that is on the initial pH of the SLC18:0 solution. Specific comments on the employment of GDL will be given in the last section of the manuscript.

Table 1 - Typical concentration values $( \pm 15 \%)$ of SLC18:0 and GDL to obtain a homogeneous hydrogel starting from a solution at $\mathrm{pH} \sim 11$.

\begin{tabular}{|c|c|}
\hline $\mathrm{C}_{\mathrm{SLC} 18: 0} / \mathrm{mg} / \mathrm{mL}$ & $\mathrm{C}_{\mathrm{GDL}} / \mathrm{mg} / \mathrm{mL}$ \\
\hline 10 & 1.8 \\
\hline 17.5 & 3.1 \\
\hline 25 & 4.5 \\
\hline 50 & 8.9 \\
\hline 75 & 13.4 \\
\hline 100 & 17.8 \\
\hline
\end{tabular}

\section{3) Controlled acidification using $\mathrm{HCl}$.}

This method was developed in this work in order to prepare reproducible SLC18:0 
hydrogels using $\mathrm{HCl}$. Manual acidification is replaced by an automated and more controlled protocol. A given $\mathrm{HCl}$ solution (normally $1 \mathrm{M}$ for a $5 \mathrm{wt} \%$ SLC18:0 solution) is placed in a syringe, which is located in a programmable syringe pump. The acidic solution is brought to the SLC18:0 vial through a thin wall microbore PTFE tube using controlled delivery rates. The apparatus is shown in Figure $\mathrm{S} 1$. In this work we have spanned the range $30<$ rate $[\mu \mathrm{L} / \mathrm{h}]<$ 6000 , corresponding to molar rates $30 \mathrm{mM} / \mathrm{h}$ and $6 \mathrm{M} / \mathrm{h}$. The SLC18:0 solution should be kept under stirring ( $300 \mathrm{rpm})$ and $\mathrm{pH}$ can be monitored so to stop $\mathrm{HCl}$ injection at the desired final $\mathrm{pH}$ value. One should note that the molarity of the $\mathrm{HCl}$ solution can vary as long as one adjusts the acid feeding rate in order to keep the overall molar rate constant and dilution factor low. For instance, hydrogels with similar properties can be obtained either with a $1 \mathrm{M} \mathrm{HCl}$ solution at a rate of $30 \mu \mathrm{L} / \mathrm{h}(30 \mathrm{mM} / \mathrm{h})$ or with a $0.5 \mathrm{M} \mathrm{HCl}$ solution at a rate of $60 \mu \mathrm{L} / \mathrm{h}(30 \mathrm{mM} / \mathrm{h})$. However using $\mathrm{HCl}$ concentrations below $0.5 \mathrm{M}$ is not recommended due to the higher amount of $\mathrm{HCl}$ needed to achieve $\mathrm{pH} \sim 6$, leading to a higher dilution of the final system.

Small Angle X-ray Scattering (SAXS). SAXS experiments are performed at $25^{\circ} \mathrm{C}$ at the DUBBLE BM26B beamline at the ESRF synchrotron facility (Grenoble, France). ${ }^{47,48}$ Samples have been analysed during the run SC4639 using a beam at $11.93 \mathrm{KeV}$ and a sample-to-detector distance of $2.10 \mathrm{~m}$. Samples are prepared and inserted in $1 \mathrm{~mm}$ quartz tubes. The signal of the Pilatus 1M 2D detector ( $172 \times 172 \mu \mathrm{m}$ pixel size $)$, used to record the data, is integrated azimuthally with PyFAI to obtain the $I(q)$ vs. $q$ spectrum $(q=4 \pi \sin \theta / \lambda$, where $2 \theta$ is the scattering angle) after masking systematically wrong pixels and the beam stop shadow. Silver behenate $\left(\mathrm{d}_{\text {ref }}=58.38 \AA\right.$ ) is used as SAXS standard to calibrate the q-scale. Data are not scaled to absolute intensity.

Rheology. Viscoelastic measurements were carried out using an Anton Paar MCR 302 rheometer equipped with parallel titanium or stainless steel sandblasted plates (diameter 25 $\mathrm{mm}$ ). All experiments were conducted at $25{ }^{\circ} \mathrm{C}$ and the temperature was controlled by the stainless steel lower plate, which is the surface of the Peltier system. During experiments, the measuring geometry was covered with a humidity chamber to minimize water evaporation. To characterize SLC18:0 hydrogels, strain sweep experiments were first conducted by changing the shear strain $(\gamma)$ from $0.001 \%$ to $100 \%$ to determine the linear viscoelastic region (LVER). After loading a new sample, values between $\gamma=0.02-0.05 \%$ within the LVER were used in the subsequent angular frequency $(\omega)$ sweep from 100 and $0.01 \mathrm{rad} . \mathrm{s}^{-1}$. To monitor the gelation 
kinetic of GDL-induced hydrogels, SLC18:0 solutions were mixed with the appropriate amount of GDL and the final mixture was vortexed for 20 seconds and immediately loaded on the bottom plate. Dynamic oscillatory time sweep experiments were performed by applying a constant oscillation frequency $\left(\omega=6.28 \mathrm{rad}^{-1} \mathrm{~s}^{-1}\right)$ and a shear strain $(\gamma)$ within the LVER and data were collected during 360 minutes. A delay of 3-4 minutes occurs between the moment of mixing and the beginning of the measurement.

${ }^{1}$ H Nuclear Magnetic Resonance (NMR): solution NMR was used to follow the kinetics of micelle-to-fiber phase transition, ${ }^{49-51}$ because it is only sensitive to fast-tumbling molecular species in solution or in micellar environments, while crystalline solids are not detected. Timeresolved ${ }^{1} \mathrm{H}$ solution NMR experiments are acquired on a Bruker Avance III 300 spectrometer using a $5 \mathrm{~mm}{ }^{1} \mathrm{H}-\mathrm{X}$ BBFO probe at $\mathrm{T}=25^{\circ} \mathrm{C}$. Number of transient is 16 with $5 \mathrm{~s}$ recycling delay. Experiments are carried out in $\mathrm{D}_{2} \mathrm{O}$ as follows: a $2.5 \mathrm{wt} \%$ concentrated solution of SLC18:0 is prepared in $99.99 \% \mathrm{D}_{2} \mathrm{O}$ at $\mathrm{pD} \sim 11$, using a $5 \mathrm{M}$ solution of $\mathrm{NaOD}(\mathrm{NaOH}$ powder dispersed in $\mathrm{D}_{2} \mathrm{O}$ ). The solution is split in half and the ${ }^{1} \mathrm{H}$ NMR spectrum of the first half is recorded. The second half is added to the corresponding amount of pre-weighted GDL (refer to Table 1) necessary to obtain a homogeneous hydrogel. The mixture is eventually vortexed and inserted in a standard $5 \mathrm{~mm}$ glass tube. A technical uncompressible delay of about 6 to 7 minutes occurs between the moment of mixing and the first recorded spectrum. The comparison between the first spectrum and the solution at basic $\mathrm{pH}$ shows no real differences between the two spectra and for this reason, the first recorded spectrum of the gelation kinetics is used for normalization. The same experiment is repeated on a solution to which the amount of GDL is doubled, so to obtain a precipitate instead of a homogeneous hydrogel. Attribution of the ${ }^{1} \mathrm{H}$ NMR spectrum of SLC18:0 is provided in detail in ref. ${ }^{32}$.

Absolute values of the peak area as a function of time are obtained using the "integration" and "relaxation" moduli of the Topspin" 3.5 pl7 version of the software, while the full width at half maximun (FWHM) profiles have been automatically obtained by using of DMFit software, available free of charge at the developer's website. ${ }^{52,53} \mathrm{We}$ have observed small phasing problems affecting the peak of $\mathrm{H}_{2} \mathrm{O}$ during the kinetics experiments. Since this is the most intense peak, poor phasing can affect the baseline in the vicinity of the anomeric $\mathrm{C} \underline{H}$ between $3 \mathrm{ppm}$ and $4.5 \mathrm{ppm}$. This unavoidable fact strongly affects the actual value of the peak area. For this reason, we only calculate the time-resolved evolution of the aliphatic peak integral contained between $0.5 \mathrm{ppm}$ and $2.5 \mathrm{ppm}$. 
Avrami plots. The Avrami equation is commonly used to determine the nucleation and growth mechanism of bulk crystals ${ }^{54,55}$ and it has been successfully applied to the study of fibrillar self-assembled gels. ${ }^{21,22,56}$ The general form of the Avrami equation is $X_{c r}=1-$ $e^{-k t^{n}}, X_{c r}$ is the volume fraction of the crystalline phase at a given time of the reaction, $k$ is the kinetic constant, $t$ is the time and $n$ is the type of nucleation (heterogeneous or instantaneous) and dimensionality of crystal growth, and where $n$ is commonly contained between 1 and 4, indicating a 1-D or fiber-like, 2-D or platelet-like and 3-D growth. The Avrami plot is generally applied in the nucleation and growth phase, so to avoid complex crystallization effects. ${ }^{57}$ Plotting $\ln \left\{-\ln \left[\left(1-X_{c r}\right)\right]\right\}$ against $\ln (t)$ gives access to $n$ (slope) and $\ln (k)$ (intercept). In this work, $X_{c r} \equiv X_{F}$, where $X_{F}$ is the fiber fraction obtained from ${ }^{1} \mathrm{H}$ NMR according to $X_{F}=\left(1-X_{M}\right)=\left(1-X_{A}\right),{ }^{58}$ where $X_{M}$ is the water-soluble micellar fraction, which is experimentally obtained from the normalized peak area at $2.5<\delta / \mathrm{ppm}<0.5$, here referred to obtained as $X_{A}$.

Cryogenic Transmission Electron Microscopy (Cryo-TEM). These experiments were carried out on an FEI Tecnai 120 twin microscope operating at $120 \mathrm{kV}$ equipped with a Gatan Orius CCD numeric camera. The sample holder was a Gatan Cryoholder (Gatan 626DH, Gatan). Digital Micrograph software was used for image acquisition. Cryofixation was done on a homemade cryofixation device. The solutions were deposited on a glow-discharged holey carbon coated TEM copper grid (Quantifoil R2/2, Germany). Excess solution was removed and the grid was immediately plunged into liquid ethane at $-180^{\circ} \mathrm{C}$ before transferring them into liquid nitrogen. All grids were kept at liquid nitrogen temperature throughout all experimentation. 


\section{Results and discussion}

\section{SLC18:0 forms hydrogels}

The micelle-to-fiber phase transition obtained by the $\mathrm{pH}$-jump method on a diluted solution (0.5 wt\%) of SLC18:0 was studied in detail in previous works by combining cryoTEM and pH-resolved in situ SAXS. ${ }^{32,59}$ In the fiber phase region, we observed that centrifugation of a stable colloidal solution of SLC18:0 can easily lead to a fiber-rich lower phase by forced syneresis. This observation suggests that SLC18:0 hydrogels can most likely be obtained by the direct $\mathrm{pH}$-jump if concentration is high enough, just as observed for analogous LMWG, where gelation is driven by $\mathrm{pH} .{ }^{18,27,60,61}$ To test this hypothesis, we prepare a series of SLC18:0 samples at various concentrations both by manual acidification using $\mathrm{HCl}$ solution $(0.5 \mathrm{M}$ or $1 \mathrm{M})$ and upon addition of GDL to the initial basic solutions at $\mathrm{pH} 11$. The first method is straightforward but more user-dependent (please, refer to the experimental section for a note on reproducibility), while the second method is user-independent, it provides homogeneous SAFIN gels ${ }^{27}$ but requires the addition of an extra molecule in close-to-equimolar amounts (here optimized at 1 SLC18:0 : 0.63 GDL) with respect to SLC18:0, and which could interfere with the self-assembly process. The rheological properties of a series of SLC18:0 samples prepared at $\mathrm{pH} 6$ and various concentrations using the above mentioned methods are shown in Figure S 2. Dynamic strain sweep experiments performed on SLC18:0 samples, prepared both by manual acidification using $\mathrm{HCl}$ (Figure $\mathrm{S} 2 \mathrm{a}$ ) and upon GDL addition (Figure S 2 b), demonstrate a typical strain softening behavior. At low shear strain values both moduli exhibit a constant value with $G^{\prime}>G^{\prime \prime}$, demonstrating the solid-like character of the samples; upon shear strain increase, both moduli decreases from a given shear strain named as critical shear strain $\left(\gamma_{c}\right)$ which is calculated from the extent of the linear stress $(\sigma)-\operatorname{strain}(\gamma)$ relationship (Figure S 2c). The extent of the linear viscoelastic regime from $\gamma_{c}$ is related to structural changes and gel disruption. At higher shear strain, a $G^{\prime}-G^{\prime \prime}$ crossover is observed and finally $G^{\prime}<G^{\prime \prime}$, reflecting the fluidization of the samples, or a gel-to-sol transition. The angular frequency-dependent storage $\left(G^{\prime}\right)$ and loss $\left(G^{\prime \prime}\right)$ moduli, measured for all samples both by manual acidification using $\mathrm{HCl}$ (Figure S 2d) and addition of GDL (Figure S 2e), show that $G^{\prime}(\omega)>G^{\prime \prime}(\omega)$, with no evidence of angular frequency dependence of the storage modulus $G^{\prime} \propto \omega^{0}$, indicating that samples are gels over the entire angular frequency range.

Whichever the acidification method, concentration has a clear impact on the strength of the hydrogels, where $2.10^{-2}<G^{\prime} / \mathrm{kPa}<2$ for manual $\mathrm{HCl}$ addition, while $2.10^{-1}<G^{\prime} / \mathrm{kPa}<200$ in GDL. However, acidification through GDL systematically provide hydrogels with elastic 
moduli in the order of two log units higher. This is summarized in profiles showing the concentration dependency of the gel plateau storage modulus $G_{0}(C)$ for both methods of acidification (Figure 2a). The $G_{0}(C)$ behavior is very useful to understand the rheological behavior of hydrogels and their structural organization, based on theoretical models, originally established for polymers but extended to fibrillary systems, because self-assembled filaments can be described as polymers with a significant bending rigidity. ${ }^{62} G_{0} \propto A C^{n}$, with $A$ being a constant and $n$ an empirical exponent, is a well-known scaling law measured in colloidal and polymer gels. ${ }^{63-65}$ From Figure $2 \mathrm{a}, G_{0}$ scales linearly with concentration with a slope contained between 2.0 and 2.4 for both manual $\mathrm{HCl}$ acidification and GDL, respectively. This experimental $G_{0}(C)$ behavior is in a good agreement with scaling laws of entangled polymers in a good solvent and in a semidilute regime with $n=2.25,{ }^{63}$ or with $n=11 / 5$, for entangled semiflexible biopolymers. ${ }^{66}$ Similar values are also found for fibrillary hydrogels composed of bacterial cellulose ${ }^{67}$ and LMWG, ${ }^{2,18,41,67}$ but one should also mention that $n=5 / 2^{66}$ was also reported for highly cross-linked semiflexible biopolymer networks. If $G_{0}(C)$ indicates that SLC18:0 samples become stiffer with concentration, they are also more sensitive to deformation, as highlighted by the decrease of the theoretical critical strain, $\gamma_{c}$ with increasing concentration (Figure $\mathrm{S} 2 \mathrm{f}$ in the supporting information and discussion therein). Such concentration dependency of $\gamma_{c}$ is commonly attributed to the reduction of the mesh size (the average spacing between fibers) and reduction of the entanglement length (distance between entanglement points). ${ }^{66}$

The normalization of the strain sweep data (Figure S 2g) highlights the strain overshoot nature of SLC18:0 samples. ${ }^{68}$ Such strain hardening overshoot was previously reported for a wide range of complex fluids like concentrated emulsions ${ }^{69}$ or microgels suspensions, ${ }^{70}$ but also for SAFIN without discussing its origin. ${ }^{71}$ Depending on the complex fluid, the origin of the strain overshoot can be attributed to an increase of the effective volume of temporal structures, ${ }^{72}$ to a variation of aggregate size in suspensions ${ }^{73}$ or to a rearrangement of clusters ${ }^{74}$ during oscillatory shear deformation. ${ }^{68}$ However it's generally assumed that weak strain overshoot is a result from the balance between the formation and the destruction of the network junctions. ${ }^{68}$ Here, we observe that the intensity of the reduced loss modulus $\left(G^{\prime \prime} / G_{0}^{\prime \prime}\right)$ does not show a clear dependence neither on the SLC18:0 concentration nor to the acidification technique (Figure S 2h-i). However, the mere presence of a strain hardening overshoot in this system indicates the statistically-relevant presence of intermediate-size structures, which under large deformation will first resist against the imposed deformation, resulting in an increase in $G^{\prime \prime}$, before breaking 
up above a given deformation limit, beyond which the SLC180 fibers align with the flow field, explaining the decrease in $G^{\prime \prime}$. The possible nature of these structures will be discussed by mean of microscopy tools, later on.

Based on the behavior of SLC18:0 samples under small and large strains, we applied three cycles of step-strain experiments to evaluate the recovery time and mechanical yield of the hydrogels after applying a large deformation (Figure 2b). During each cycle, samples are first subjected to a constant strain of $0.02 \%$ (in the linear viscoelastic regime, $0.02 \%<\gamma_{c}$ ) before increasing the strain from $0.1 \%$ to $100 \%$ during 2 min (large deformation, $100 \% \gg \gamma_{c}$ ) and the strain is decreased again from $100 \%$ to $0.02 \%$ for 30 minutes. For both SLC18:0 samples prepared using either $\mathrm{HCl}$ or GDL, it was observed that before applying the first large deformation, $G^{\prime}$ is constant and greater than $G^{\prime \prime}$; however, when a large deformation is applied, $G^{\prime}$ becomes lower than $G^{\prime \prime}$, demonstrating the liquid-like behavior of these gel at high strain values. Immediately after removing the 100\% strain, SLC18:0 hydrogels prepared using $\mathrm{HCl}$ and GDL respectively recovered $82 \%$ and $77 \%$ of their original stiffness (average values after three cycles). After three cycles, the average complete recovery time is estimated to be $\sim 7 \mathrm{~min}$ and $\sim 3$ min for SLC180 hydrogels prepared using $\mathrm{HCl}$ and GDL, respectively. The interesting recovery yield and time (few minutes) highlight the self-healing feature of the SLC18:0 hydrogels.

The rheological characterization of SLC18:0 samples prepared both by manual acidification using $\mathrm{HCl}$ and addition of GDL (molar ratio of 1 SLC18:0 : 0.63 GDL) demonstrate the successful preparation of SLC180 hydrogels with interesting mechanical properties (stiffness and self-healing properties). We highlight two important points:

1) The gain in magnitude of the storage modulus $G^{\prime}(\omega)$ between the $\mathrm{HCl}$ and GDL approach is close to two orders of magnitude in favour of the GDL approach. This observation is not surprising and is comparable to what was reported for Fmoc conjugated peptides, ${ }^{16,27,28,31}$ where GDL-driven gelation was implemented to prepare repeatable homogeneous and strong fibrillar hydrogels. Our results confirm the true interest in using GDL over manual $\mathrm{HCl} \mathrm{pH}$ variations also for the SLC18:0 LMWG.

2) The $G_{0}(C)$ behavior of SLC18:0 samples span between theoretical prediction of hydrogels driven by entanglement, although cross-linking due to tip- and side-branching should not be excluded: highly cross-linked semiflexible biopolymer networks have shown an exponent of $\mathrm{n}=5 / 2$, as predicted by the Mackintosh, Käs and Janmey theory. ${ }^{66}$ Moreover, similar exponents were also attributed to cross-linking LMWG-derived hydrogels. ${ }^{2,75}$ 
If these interesting results class SLC18:0 as a new LMWG, similarly to FMOC

368 derivatives and other carbohydrate-based compounds, ${ }^{76-80}$ we must highlight a drastic userdependent reproducibility of the hydrogels both when using $\mathrm{HCl}$ and non-optimized GDL addition. We have in fact experienced many failures, consisting in powder precipitation instead of hydrogel formation, while reducing the $\mathrm{pH}$. Considering that all experiments within a given method are performed under equal conditions of temperature, initial $\mathrm{pH}$ and dilution factors, we make the hypothesis that the rate of $\mathrm{pH}$ change may have crucial effects in the mechanical properties of gel.

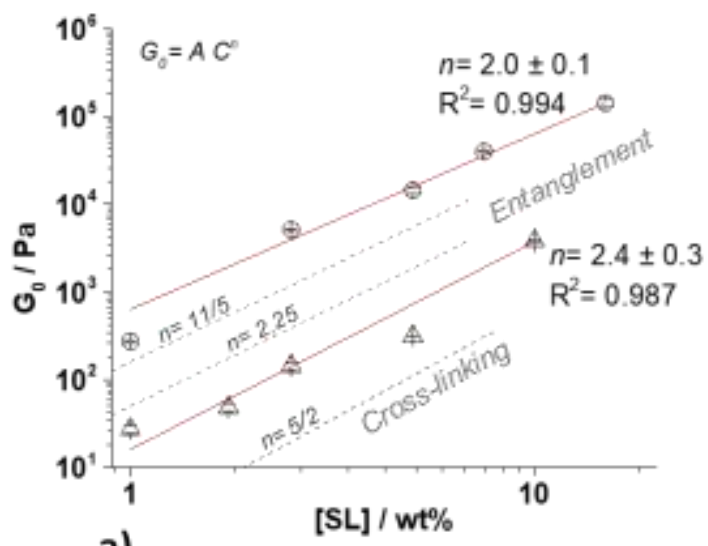

a)

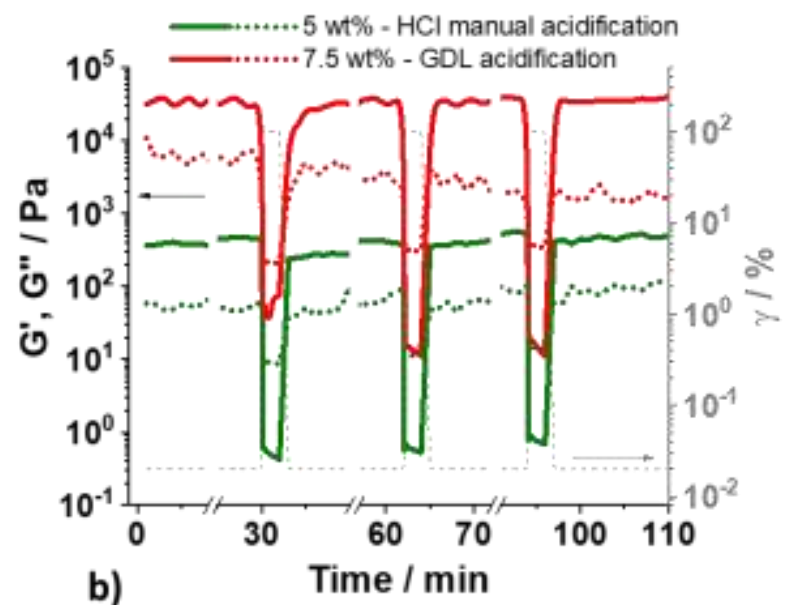

Figure 2 - a) Evolution of the plateau modulus $\left(G_{0}\right)$ with SLC18:0 concentration at pH 6. Gels are prepared both by manual acidification using HCl $1 \mathrm{M}$ (triangles) and upon GDL addition (circles, molar ratio 1 SLC18 : 0.63 GDL) to basic SLC18:0 solution (initial pH 11). The dashed lines are theoretical scaling predictions for entangled semiflexible polymers (De Gennes, $n=2.25 ;{ }^{63}$ Mackintosh et al., $n=11 / 5$ ) ${ }^{66}$ and cross-linked networks (Mackintosh et al., $n=5 / 2) .{ }^{66} \mathrm{~b}$ ) Three cycles of step-strain experiments $(\omega=6.28$ rad.s $\mathrm{s}^{-1}$, destructuring at $\gamma=100 \%$ during 2 min followed by recovery at $\gamma=0.02 \%$ during $30 \mathrm{~min}$ ).

\section{The acidification rate controls the mechanical properties}

If manual addition of $\mathrm{HCl}$ has long been questioned to provide hydrogels with lower elastic moduli ${ }^{27}$ and probably being one of the reasons for poor quantitative agreement in terms of hydrogel mechanical properties among different authors, ${ }^{16}$ the impact of GDL amount on the gel properties has equally been questioned. ${ }^{31} \mathrm{We}$ have ourselves tested several SLC18:0:GDL molar ratios and we surprisingly observe that above an optimal amount of GDL, which is empirically set at approximately 1:0.63 $( \pm 15 \%)$, a powdery precipitate is systematically observed. Similarly, lower GDL amounts do not promote gelation, because $\mathrm{pH}$ remains above the micelle-to-fiber phase transition. To prove the direct impact of $\mathrm{pH}$ rate change on the 
hydrogel mechanical properties, we have also prepared several hydrogels replacing the standard manual $\mathrm{HCl} 1 \mathrm{M}$ addition (concentration of SLC18:0 was $5 \mathrm{wt} \%$ ) with a controlled rate by mean of a syringe pump (apparatus is shown in Figure $\mathrm{S}$ 1). We have spanned the $\mathrm{pH}$ change rates over two orders of magnitude, between $30 \mu \mathrm{L} / \mathrm{h}$ and $6000 \mu \mathrm{L} / \mathrm{h}$. Figure $3 \mathrm{a}$ and Figure $3 \mathrm{~b}$ respectively report the corresponding time-dependent $\mathrm{pH}$ profiles, while the mechanical properties of the final hydrogels prepared using both $\mathrm{HCl}$ at different acidification rates and with different GDL amounts are given in Figure 3c-e.

For samples prepared using GDL, the evolution of the $\mathrm{pH}$ of a SLC18:0 $1 \mathrm{wt} \%$ solution with time at three GDL molar ratios $(0.63,0.94,1.25)$ is shown in Figure $3 b$, while the corresponding evolutions of $G^{\prime}$ are given in Figure 3c. For GDL ratios below 0.94, a homogeneous hydrogel is systematically obtained, while at 1.25 the solution has practically no mechanical properties and a powder precipitate is generally observed at the bottom of the vial. The $\mathrm{pH}$ drop profiles with time (Figure $3 \mathrm{~b}$ ) show indeed that the rate of $\mathrm{pH}$ change is the same for all samples below $20 \mathrm{~min}$, that is during the initial hydrolysis of GDL and until $\mathrm{pH}$ settles between 7 and 7.4. Above $20 \mathrm{~min}$, the largest amount of GDL (1.25) induces a faster decay in $\mathrm{pH}$ for a final $\mathrm{pH}$ below 5 after $250 \mathrm{~min}$, compared to about $6 / 6.5$ for lower GDL amounts. If similar differences in terms of $\mathrm{pH}$ decay rate have been observed by Adams et al., ${ }^{31}$ they did not observe an impact on the gel mechanical properties, which was rather affected by the value of the final $\mathrm{pH}^{2,30,31}$ In this work, precipitation occurs as early as 30-40 min after excess of GDL is added, that is when pH is still sufficiently high (between 6 and 7), in contrast to what was found with Fmoc-conjugated peptides. If final $\mathrm{pH}$ effects are excluded in this system, this point will be commented in more detail in the last section of this manuscript.

For $5 \mathrm{wt} \%$ SLC18:0 hydrogels prepared using $\mathrm{HCl}$ at different acidification rates, at $6000 \mu \mathrm{L} / \mathrm{h}$ (black squares), the $\mathrm{pH}$ drops below 6 within 1 minute and a powder is immediately obtained. The corresponding $G^{\prime}(\sim 1 \mathrm{~Pa}$, Figure $3 \mathrm{e})$ is practically not significant but it is analogous to the plateau modulus of GDL at 1.25 molar ratio (magenta hexagons, Figure $3 \mathrm{c}$ ). At lower $\mathrm{HCl}$ addition rates (between 100 and $1000 \mu \mathrm{L} / \mathrm{h}$ ), the mechanical properties gradually increase (Figure 3e) up to the $\mathrm{kPa}$ domain. The elastic modulus becomes comparable with a 5 wt $\%$ gel obtained with manual addition of $\mathrm{HCl}$ (Figure 3d), but also with a $1 \mathrm{wt} \%$ gel obtained by using optimal amounts of GDL (black squares, Figure 3c). Very interestingly, for very small $\mathrm{HCl}$ addition rates $(30 \mu \mathrm{L} / \mathrm{h})$ the time evolution of $\mathrm{pH}$ (diamonds, Figure 3a) matches exactly the time-dependent $\mathrm{pH}$ profiles recorded in the presence of GDL at 0.63 and 0.94 molar ratios (black and red-segmented lines, Figure 3b) up to $100 \mathrm{~min}$. The elastic modulus of the SLC18:0 $5 \mathrm{wt} \%$ hydrogel obtained at a $\mathrm{HCl}$ addition rate of $30 \mu \mathrm{L} / \mathrm{h}$ (Figure $3 \mathrm{e}$ ) is now one order of 
magnitude superior if compared to a $5 \mathrm{wt} \%$ gel obtained by the manual $\mathrm{HCl}$ method (Figure 3d) and only a factor two (linear scale) lower compared to a $5 \mathrm{wt} \%$ SLC18:0 hydrogel obtained by GDL (Figure 3d). In clear, at constant $\mathrm{pH}$ (here, 6) and concentration (5 wt\%), controlling the acidification rate below $50 \mu \mathrm{L} / \mathrm{h}$ generates the same time-dependent evolution of $\mathrm{pH}$ compared to GDL (up to $100 \mathrm{~min}$ ) and is responsible for a 50-fold improvement in the elastic modulus compared to manual $\mathrm{HCl}$ addition. On the other hand, data in Figure 3d,e also indicate that manual $\mathrm{pH}$ variation, although more difficult to reproduce, can still produce hydrogels with interesting, yet not optimized, mechanical properties.

One can conclude that homogeneous and tough hydrogels with comparable elastic moduli could be obtained both by GDL and $\mathrm{HCl}$, provided a very low $(<30 \mu \mathrm{L} / \mathrm{h}$ for a typical $\mathrm{HCl} 1 \mathrm{M}$ used in SLC18:0 at $\mathrm{C}=5 \mathrm{wt} \%$ ) acidification rate when employing a $\mathrm{HCl}$ solution (more general considerations on the acidification rates expressed in terms of $\mathrm{mM} / \mathrm{h}$ are commented in the last section of the manuscript). Gels are generally formed during the $\mathrm{pH}-$ lowering process but, as expected, hardening occurs after one to two hours after removing the magnetic stirrer shear. Uncontrolled acidification rates certainly explain part of the discrepancies in terms of mechanical properties of LMWG hydrogels found in the literature. ${ }^{16,27}$ Moreover, other parameter like stirring (i.e., shearing the sample during hydrogel formation and fiber growth) during $\mathrm{HCl}$ acidification were also suggested to affect the hydrogels mechanical properties, and which promoted the use of GDL in the past. ${ }^{29}$

As a last remark, we highlights that for sufficiently low $\mathrm{HCl}$ acidification rates and for optimum GDL amounts, the $\mathrm{pH}$ rises shortly after an initial abrupt drop and before decreasing again. The length and moment in time of the $\mathrm{pH}$ rise varies with the acidification rate (or GDL amount) but it is systematically observed. Adams et al., ${ }^{49,81}$ as well as other authors ${ }^{82}$ reported the same phenomenon on Fmoc-conjugated peptides acidified with GDL and they attributed it to the difference between the $\mathrm{pKa}$ of the monomer with respect to the apparent $\mathrm{pKa}$ corresponding to the self-assembled peptide. This is most likely due to the well-known charge compensating process, that lies behind the origin of the apparent pka, a phenomenon often observed in self-assembled fatty acids. When fatty acids assemble into a crystal or even a lamellar phase, the surface charge density is initially neutralized by a diffusion of protons form the bulk solution, which is the origin of the temporary raise in bulk $\mathrm{pH} .{ }^{83-85}$ 

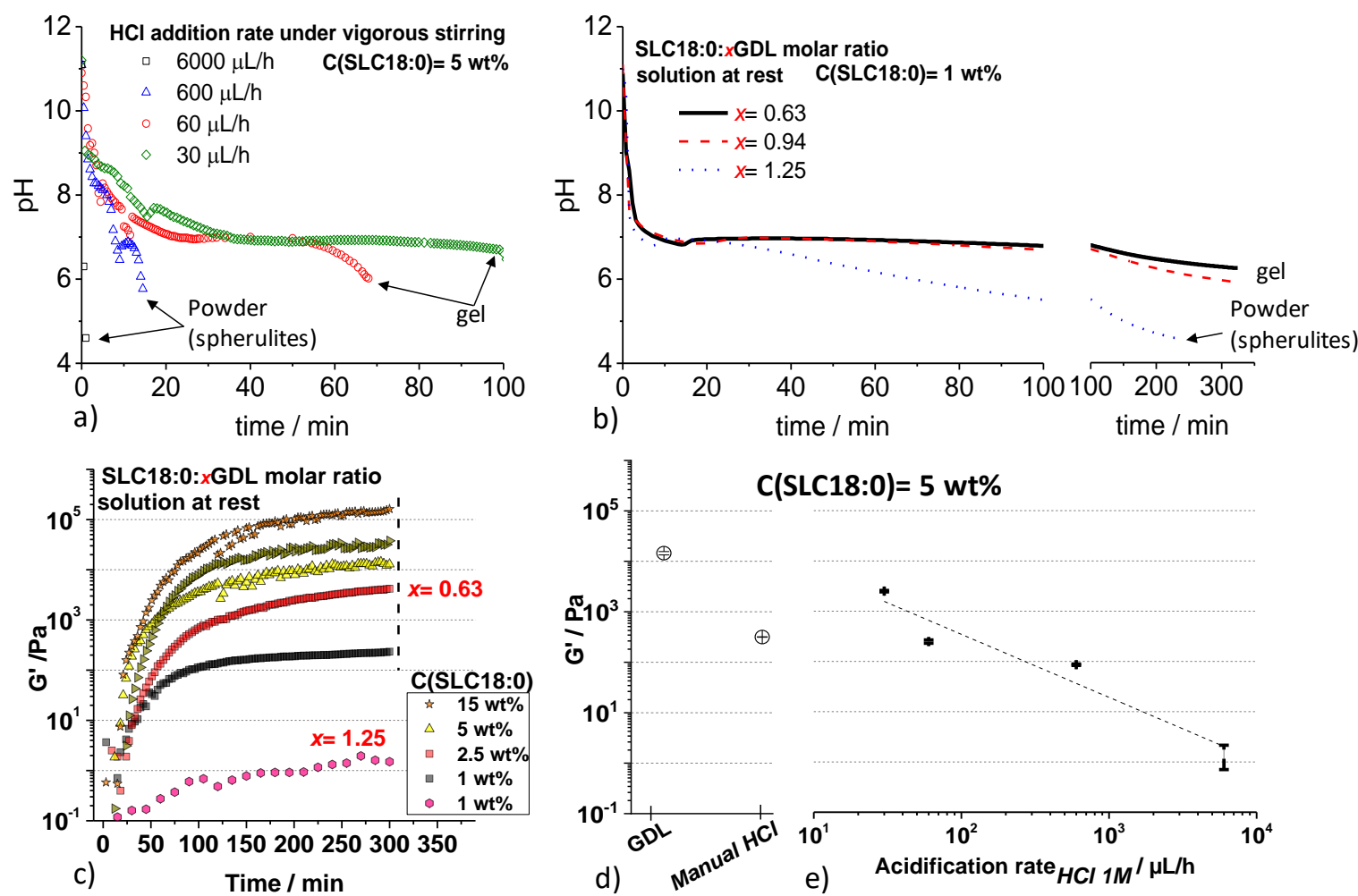

Figure 3 - Time evolution of pH time measured for SLC18:0 solutions (V=1 mL) at a starting pH 11. In a), the pH of $5 \mathrm{wt} \%$ SLC18:0 solutions is lowered under stirring ( $300 \mathrm{rpm})$ using controlled rates of addition of HCl $1 \mathrm{M}$. In b), the pH is lowered for a $1 \mathrm{wt} \% \mathrm{SLC18:0}$ at $\mathrm{pH} 11(\mathrm{~V}=1 \mathrm{~mL})$ upon vortexing $(20 \mathrm{~s}-30 \mathrm{~s})$ with GDL, where $x$ stands for the GDL molar ratio with respect to one mole of SLC18:0. The solution is left at rest after vortexing. c) Time evolution of the elastic moduli (data are collected in the linear domain, $\omega=$ 6.28 rad.s $^{-1} ; \gamma=0.02 \%$ ) of SLC18:0 solutions at various concentrations upon mixing with GDL. d) Plateau elastic moduli measured at $5 \mathrm{wt} \%$ using the GDL and manual HCl methods. e) Evolution of the plateau elastic moduli ( $\omega=6.28 \mathrm{rad} . \mathrm{s}^{-1}, \gamma=0.02 \%$, each point is averaged over 10 minutes of acquisition) for a series of $5 \mathrm{wt} \%$ SLC18:0 hydrogels prepared from $\mathrm{pH} 11$ with various rates of addition of a $1 \mathrm{M}$ HCl solution.

Supersaturation and spherulite formation depend on the $\mathrm{pH}$ change rate. A multiscale analysis.

The data presented above are in contrast, to the best of our knowledge, with the existing literature on the mechanistic aspects of $\mathrm{pH}$-driven hydrogels for LMWG (mainly recorded on Fmoc-conjugated peptides), and which is based on the following. GDL is preferred to $\mathrm{HCl}$ and it always gives a homogeneous fibrillar hydrogel. This is shown by Adams ${ }^{16,27,31}$ and confirmed by micro-rheology data; ${ }^{82,86}$ the rate of $\mathrm{pH}$ change has little influence on the gel mechanical properties, which are rather governed by the final $\mathrm{pH}^{2,30,31}$

To better understand the discrepancy between the mechanism of formation of SLC18:0 hydrogels and Fmoc-conjugated peptides, we investigate the structural and morphological properties of the fibers over a broad scale, from the nanometer to the micrometer range, 
combining SAXS, cryo-TEM and optical microscopy. Data on the kinetics of fiber formation are also evaluated by ${ }^{1} \mathrm{H}$ NMR. It is important to stress that, in order to avoid artifacts, all experiments have been collected on wet samples and no observation has been performed on neither air dried nor freeze-dried samples.

The nanoscale structure of the hydrogels prepared both with $\mathrm{HCl}$ and GDL has been studied with SAXS, presented in Figure S 3. The SAXS profiles of hydrogels obtained with $\mathrm{HCl}$ and GDL (Figure S 3a) and with GDL at $x=0.63$ (hydrogel) and $x=2.52$ (powder precipitate) (Figure S 3b) are all comparable and they are the typical fingerprint of SLC18:0 twisted ribbons, as described elsewhere. ${ }^{59,87}$ All data are characterized by a broad diffraction peak at $\mathrm{q}=2.36 \mathrm{~nm}^{-1}$, indicative of the lipid packing in the ribbon plane, an oscillation at about $0.75 \mathrm{~nm}^{-1}$, probably indicating the ribbon form factor, and a strong low-q scattering with no plateau. The fibrillary and twisted ribbon morphology is confirmed at a larger scale (>100 nm) by cryo-TEM experiments presented in Figure 4a1, Figure $4 \mathrm{~b} 2$ and Figure $4 \mathrm{c} 2$ for, respectively, $\mathrm{HCl}$ (5 M, powder), GDL ( $x=0.63$, hydrogel $)$ and GDL $(x=2.52$, powder $)$ samples. Combination of SAXS and cryo-TEM irrefutably show that neither GDL at any amount nor the $\mathrm{pH}$-change rate have perturbed the formation of twisted ribbons and the packing of SLC18:0 within the ribbons. The poorer mechanical properties observed for excess of GDL and fast $\mathrm{pH}$ change rates must then be explained by differences in the morphology/aggregation at a larger scale. Cryo-TEM of the powder precipitates obtained either by employing $5 \mathrm{M} \mathrm{HCl}$ (Figure $4 \mathrm{a} 2$ ) or GDL $x=1.25$ (Figure 4c1, Figure 4c2) shows both spherulitic aggregates (Figure 4a2) and side branching (Figure 4c1, Figure 4c2). On the contrary, cryo-TEM corresponding to a stable hydrogel obtained with $x=0.63$ GDL shows a homogeneous network of twisted ribbons with little amount of spherulites and side-branched fibers. One should observe nonetheless that the fiber cross section is heterogeneous, whichever the approach employed; diameters varying between $10 \mathrm{~nm}$ to $50 \mathrm{~nm}$ are not uncommon in none of the samples, as already observed in more diluted SLC18:0 systems; ${ }^{32,87}$ fibers of high cross-sectional uniformity could only be obtained after dialysis. ${ }^{87}$ 

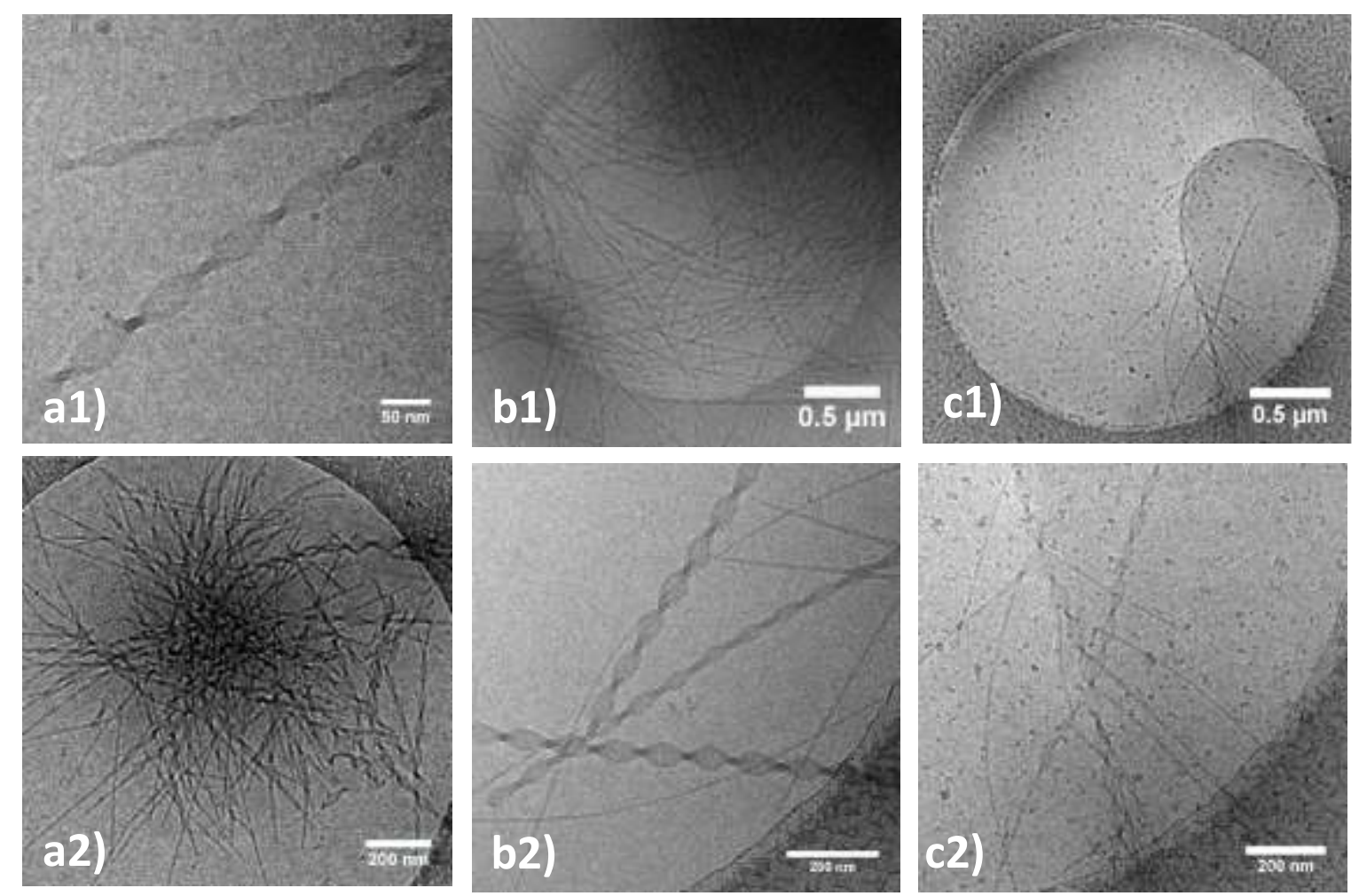

Figure 4 - a-c) Cryo-TEM images recorded on a series of samples prepared at $0.5 \mathrm{wt} \%$ SLC18:0 and acidified using a1-a2) $5 \mathrm{M} \mathrm{HCl}$ (powder precipitate), and SLC18:0: $x$ GDL, with b1-b2) $x=0.63$, c1-c2) $x=$ 1.25 .

Further observations at a larger scale using optical microscopy confirm the above assumptions. A homogeneous gel (obtained with $x=0.63 \mathrm{GDL}$ ) displays a broad fibrillar network (SLC18:0 at $1 \mathrm{wt} \%$ ), where sporadic nucleation centers are not uncommon (Figure 5a). Similar results are obtained for the hydrogel prepared at $5 \mathrm{wt} \%$ using $\mathrm{HCl}$ at a rate of $60 \mu \mathrm{L} / \mathrm{h}$ (Figure 5c). In contrast, spherulites strongly characterize those samples that form a precipitate in solution, regardless the method of preparation: excess of GDL ( $x=1.25$, Figure $5 b)$ and fast $\mathrm{HCl}$ rates $(6000 \mu \mathrm{L} / \mathrm{h}$, Figure $5 \mathrm{~d})$. Interestingly, the presence of both spherulites and branched interconnected fibers is compatible, and it can actually explain, the peculiar strain hardening overshoot characterizing the strain sweep data (Figure $S$ 2a,b), and put in evidence in the reduced viscous modulus $\left(G^{\prime \prime} / G_{0}^{\prime \prime}\right)$ as function of the reduced shear strain $\left(\gamma / \gamma_{c}\right)$ profiles

512 (Figure S 2g,h,i). Rheology data, briefly commented in the mechanical properties section and, 513 more extensively, in the Supporing Information, the support the existence of spherulites and branched structures from a statistical point of view. 

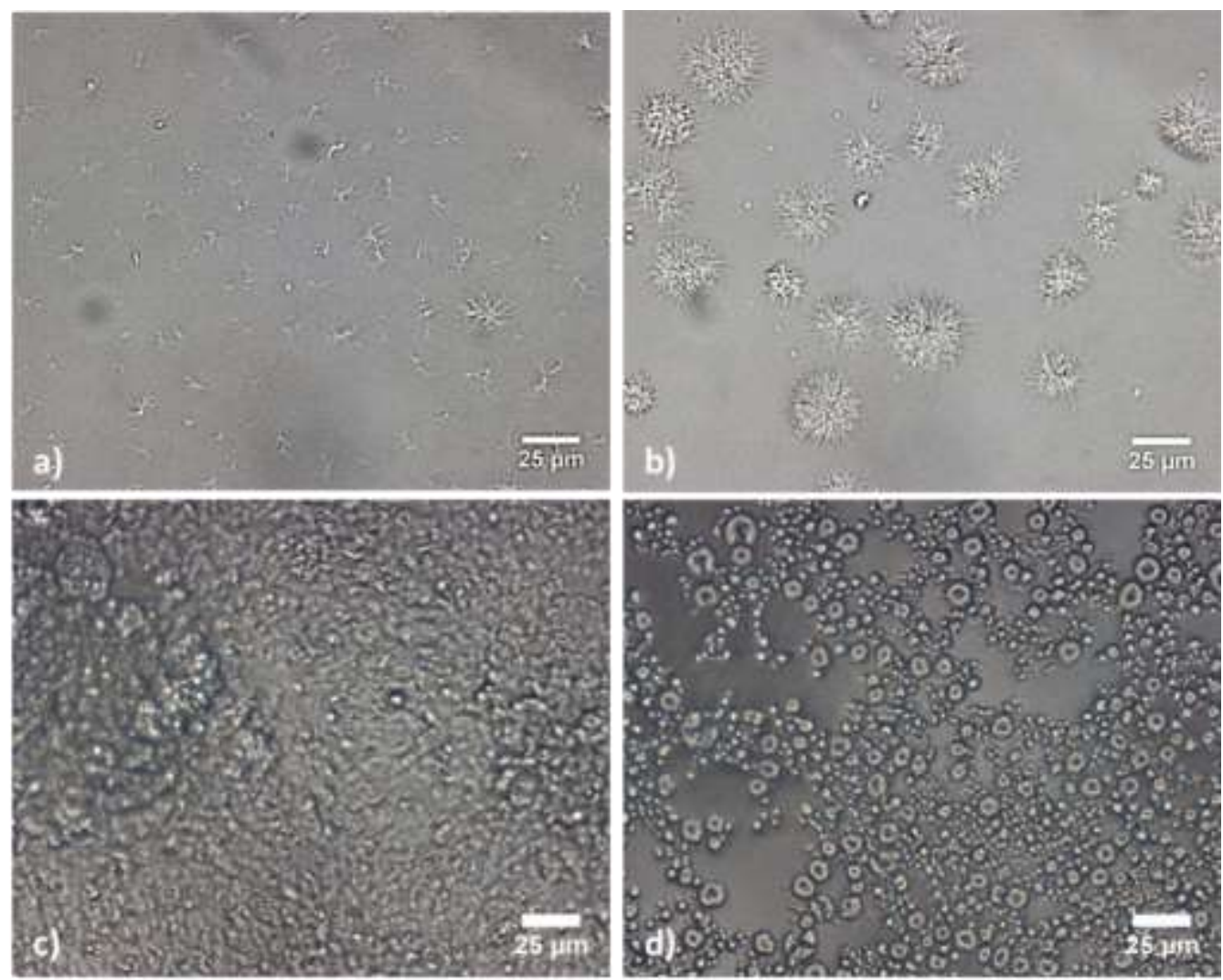

Figure 5- a,b) Optical microscopy images of SLC18:0 (1 wt \%) after $x$ GDL with a) $x=0.63$ and b) $x=1.25$, being the SLC18:0:xGDL molar ratio. c,d) Optical microscopy of SLC18:0 (5 wt \%) after HCI (1 M) addition at c) $60 \mu \mathrm{L} / \mathrm{h}$ and d) $6000 \mu \mathrm{L} / \mathrm{h}$. For all samples, initial $\mathrm{pH} \sim 11$ and final $\mathrm{pH}$ is contained between 6 and 6.5 .

The kinetics of crystallization can be followed via ${ }^{1} \mathrm{H}$ NMR spectroscopy, which is only sensitive to the compound in a fast-tumbling (e.g., micellar phase), but not crystalline, environment (e.g., fibers). Figure $S 4$ a shows the evolution of the crystalline fraction (as defined in the materials and method section), $X_{C}$, of SLC18:0 (2.5 wt \%) with time after adding GDL at $x=0.63$ and $x=1.25$, where the former produces a homogeneous gel and the latter a powder precipitate. In both cases, the final $X_{C}$ is about 0.8 , thus excluding the possibility that the poor mechanical properties in the $x=1.25$ GDL sample depend to a smaller fraction of self-assembled fibers. The time evolution of the full width at half maximum (FWHM) shows larger values for the gel (up to $35 \mathrm{~Hz}$ compared to $\sim 25 \mathrm{~Hz}$ for the powder), in agreement with a more homogeneous environment, where the mobility of micellar SLC18:0 is further reduced due to hydrogel formation. One should note that the discontinuities in both $X_{C}$ and FWHM plots are most likely artifacts due to problems in a satisfactory baseline subtraction and consequently to the signal integration, as explained in the materials and methods section.

The multi-scale study shows that the only major difference between two SLC18:0 samples prepared at the same concentation and temperature but different $\mathrm{pH}$ change rates (either 
535

536

537

538

539

540

541

542

543

544

545

546

547

548

549

550

551

552

553

\section{7}

using GDL or $\mathrm{HCl}$ ) is constituted by the morphology at the micron scale: spherulites, originated by tip- and side-branching phenomena during crystallization and growth, are systematically detected. Previous studies on $\mathrm{pH}$-driven formation of hydrogels using LMWG did not show similar features and spherulitic domains where only obtained in solvent-triggered gels. ${ }^{2,16,88}$ Tip- and side-branching phenomena are well-documented in LMWG systems, they are wellunderstood and described for temperature-driven hydro and oleogels. ${ }^{21,22,43,44}$ The correlation between mechanical properties of the gel and branching was also established: at high branching degree, spherulites dominate the gel and the mechnical properties become lower than in more homogeneous gels. ${ }^{42,44}$

Branching occurs when growth prevails over nucleation rate. When nucleation occurs at the surface of an existing fiber, the crystallographic mismatch nucleation barrier is inversely proportional to supersaturation, $\sigma$,

$$
\sigma=\frac{C-C_{e q}}{C_{e q}}
$$

where $C$ is the actual molar fraction and $C_{e q}$ the equilibrium molar fraction of a solute in solution at a given temperature. It has been widely demonstrated for LMWG that the higher the supersaturation, the lower the mismatch nucleation barrier, the higher the branching degree, with a consequent loss in the mechanical properties. If temperature, cooling rate and even seeding are commonly regarded at as the main factors impacting supersaturation in LMWG, $\mathrm{pH}$ variation was seldom systematically investigatigated. 


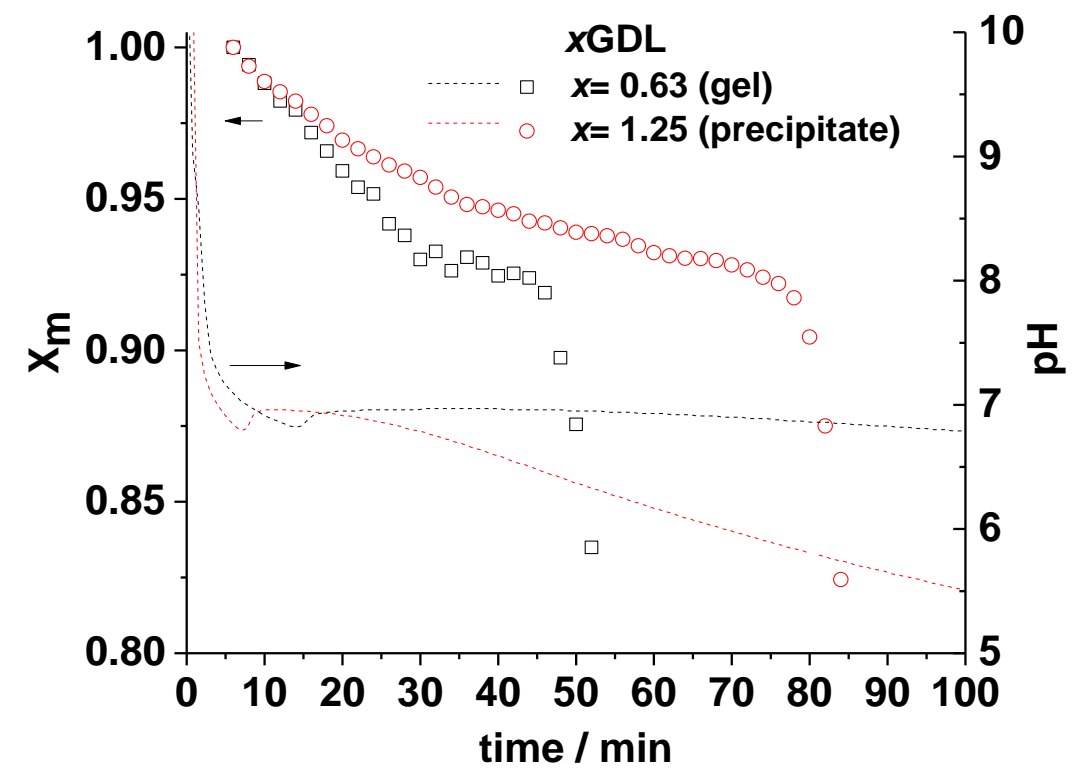

554

555

556

557

558

559

560

561

562

563

564

565

566

567

568

569

570

571

572

573

Figure 6- Time-evolution of the soluble micellar molar fraction, $X_{m}$, of SLC18:0 (2.5 wt\%) in water upon addition of optimum $(x=0.63)$ and excess $(x=1.25)$ of GDL. The pH change profile is also provided. Initial pH is 11. $x$ is the amount of GDL in the molar ratio SLC18:0:xGDL.

Figure 6 demonstrates the link between $\mathrm{pH}$ rate change and supersaturation according to the assumption that $\sigma$ is not only temperature but also $\mathrm{pH}$-dependent, $\sigma(p H)$. In this case, Eq. 1 can be rewritten as in Eq. 2, where dependency on $\mathrm{pH}$ is now explicited and dependency on temperature is omitted, assuming that all experiments are performed at the same temperature.

$$
\sigma(p H)=\frac{C(p H)-C_{e q}(p H)}{C_{e q}(p H)}
$$

$C_{e q}(p H)$ is now the $\mathrm{pH}$-dependent equilibrium concentration of SLC18:0; although we do not know the exact values, $C_{e q}(p H)$ is inversely proportional to the concentration of $\left[\mathrm{H}^{+}\right]$in solution (SLC18:0 precipitates in the form of twsted ribbons by lowering the $\mathrm{pH}$ ). $C(p H)$, on the contrary, can be estimated through ${ }^{1} \mathrm{H}$ NMR and its evolution with $\mathrm{pH}$ is simply $C(p H)=C_{p H 11} * X_{m}(p H)$, where $C_{p H 11}$ is the SLC18:0 concentration at $\mathrm{pH} \sim 11$, when it is totally dissolved in solution, and $X_{m}(p H)$ is the molar fraction of SLC18:0 in a micellar environnement determined through ${ }^{1} \mathrm{H}$ NMR. Eq. 2 can then be rewritten and rearranged as a function of $X_{m}(p H)$, as follows,

$$
\sigma(p H)=X_{m}(p H) \frac{C_{p H 11}}{C_{e q}(p H)}-1
$$


When $\mathrm{pH}$ decreases, $\frac{C_{p H 11}}{C_{e q}(p H)}$ is always higher than 1 and it is independent of the $\mathrm{pH}$ change rate. On the contrary, even if $\lim _{p H \rightarrow a c i d} X_{m}(p H) \simeq 0$, the rate at which this event occurs may vary from system to system. $\sigma(p H)$ is then maximized when $\mathrm{pH}$ is low (small $C_{e q}(p H)$ ) and when $\lim _{p H \rightarrow \text { acid }} X_{m}(p H)$ remains close to 1 as long as possible. In other words, if $X_{m}(p H)$ is close to unity all along the decrease in $\mathrm{pH}$, supersaturation is enhanced and branching occurs. This is experimntally observed for the SLC18:0. Figure 6 shows that $x=0.63 \mathrm{GDL}$ after about $70 \mathrm{~min}$, $\mathrm{pH} \sim 6$ and $X_{m}$ has dropped much below 0.8 . In this case, one expects small supersaturation and low branching: at $x=0.63$ GDL a homogeneous hydrogel is always obtained for any SLC18:0 concentration (Figure 3d, Figure 3c). On the contrary, in excess of GDL, $X_{m}(p H)$ decreases at a much slower rate, while $\mathrm{pH}$ drops fast: after $70 \mathrm{~min}, \mathrm{pH} \sim 6$ and $X_{m} \sim 0.92$. In this case, supersaturation and branching are promoted, as verified experimentally (Figure $4 \mathrm{c} 1, \mathrm{c} 2$, Figure $5 b, d)$.

The following intriguing question should be answered at this point: why do $\mathrm{pH}$ change rate and supersaturation have such an impact on the self-assembly of SLC18:0, while they do not on the hydrogel formation of most Fmoc-conjugated peptides, for which GDL concetrations as high as $2 \mathrm{M}$ are used to form stable hydrogels? ${ }^{27}$ To answer this question one could question both the probability and diffusivity of the acido-base reaction in our system. Literature data concerning SAFiN hydrogels based on Fmoc-conjugated peptides suggest that in the general $R-\mathrm{COO}^{-}+H^{+} \rightleftarrows R-\mathrm{COOH}$ ( $R$ being a general aliphatic backbone) equilibrium, the reaction is shifted towards the acid, of which the formation is fast upon acidification and diffusion is rapid. On the contrary, the data presented in this work on the SAFiN hydrogel formation of SLC18:0 suggest small reaction probabilities and/or slow diffusion. At a molecular level, the presence of a micellar phase at basic $\mathrm{pH}$ for SLC18:0 ${ }^{32,89}$ could explain the discrepancy between SLC18:0 and the literature. Two possible sources of rate-limiting steps can be identified: 1) low reaction probability of the hydronium ions with the carboxylate groups; 2) slow diffusion of $\mathrm{R}-\mathrm{COOH}$ from the micelle to the nucleation site. Although, at present, none of these hypotheses can be easily verified, we can formulate the following comments. Reaction rates in micellar solution are well-known to be affected by the presence of the micelles. ${ }^{90}$ In the present system, it could be possible that the reaction probability between hydronium ions and the carboxylate group in the micelle is not high because the latter does not necessarely lie at the micelle-water palisade, as in classical head-tail surfactant micelles, but it could diffuse between the micelle interior and surface. SLC18:0 is a bolaamphiphile and its 
micellar structure is not as well-defined as the structure of a common head-tail surfactant. We have specifically studied the structure of sophorolipid micelles ${ }^{89,91}$ and found that the carboxilic group could be located within the entire volume of the micelle. In the second hypothesis, two scenarios could hold. In the first one, the diffusion rate of a single SLC18:0 molecule after protonation is slow compared to the $\mathrm{pH}$ change rate; in the second scenario, the micellar aggregate is able to retain a critical number of protonated SLC18:0 and above which the micelle burst out, thus releasing its entire molecular population, which diffuses immediately towards a nucleation site. Unfortunately, we do not dispose of any quantitative data to support these scenarios, but we have nonetheless shown that the micelle-to-fiber transition in SLC18:0 occurs in a narrow $\mathrm{pH}$ range and without any morphological transition between the micelle and the fiber, possibly supporting the second scenario. ${ }^{89}$ It goes without saying that further understanding of the nature of the supersaturation requires further experimental data, but this is out of the scope of this work. Nonetheless, Avrami plots (please refer to the materials and method section form more information) for the gel and powder samples obtained from ${ }^{1} \mathrm{H}$ NMR data (Figure S 4c) indicate a value for the exponent $n=0.45$, where values of $n$ below unity, although uncommon, are typically found in systems with diffusion-controlled crystallization growth and heterogenous nucleation, ${ }^{56,57,92,93}$ thus supporting the overall mechanistic hypothesis.

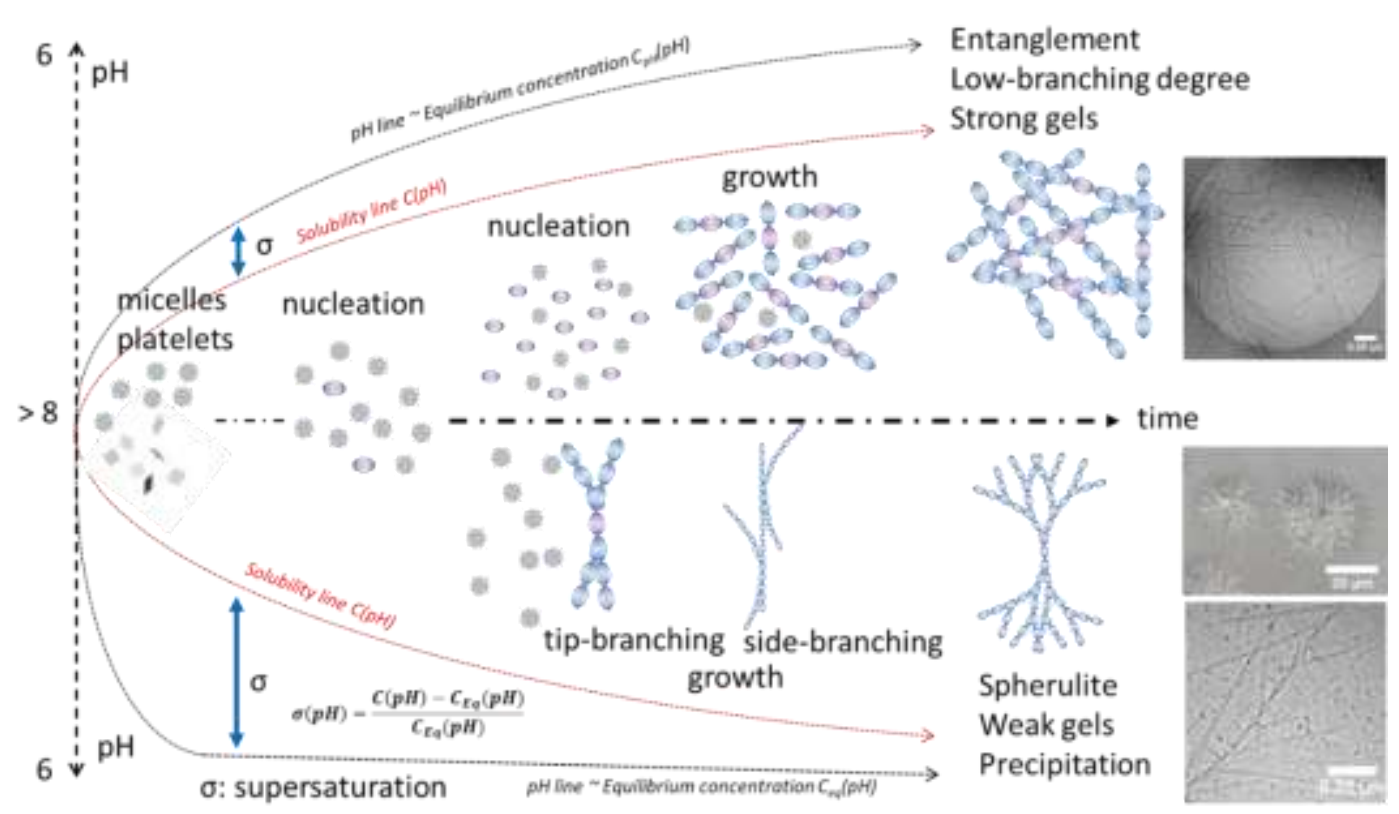

Figure 7- The pH-dependent mechanism of hydrogelation of SLC18:0 (at room temperature) strongly depends on the supersaturation level of the solution. For slow $\mathrm{pH}$ variations in time (black curve on top), supersaturation is low and the SAFiN is compatible with a diffusion-limited nucleation and growth of the fibers, leading to homogenous tough gels. For fast pH variations in time (black curve on the bottom), 
supersaturation is high and the fibrillary network is rich in side branching and spherulites, leading to weak gels or loss of a gel due to precipitation. The red dotted line represents the theoretical solubility line of SLC18:0 with pH.

Figure 7 summarizes the main findings of this work; at basic $\mathrm{pH}$, which can be contained between 8 and 11, SLC18:0 is soluble in water in its ionic form and from previous studies we know that it forms micelles, although coexisting with a minority of nanoscale platelets (these can be actually visible in suspension by the eye at $\mathrm{pH}$ above $10.5-11) .{ }^{32,46,59}$ When $\mathrm{pH}$ is reduced gradually (upper part of scheme in Figure 7 at controlled low rates $(<\sim 50 \mathrm{mM} / \mathrm{h}$, please refer to the last section for more comments on the rate), either using GDL or $\mathrm{HCl}$, both acido-base reactions at the micelle-water palisade and diffusion of SLC18:0 molecules from the micellar environment to the nucleation sites are allowed enough time to occur. Growth can then take place without crystallographic mismatch, because supersaturation is kept at minimum due to the fact that the molar fraction of soluble solute follows the reduction in the equilibrium concentration at each $\mathrm{pH}$. A homogeneous fiber network with low degree of branching is eventually formed and the hydrogel mechanical properties are maximized. On the opposite, if $\mathrm{pH}$ is decreased rapidly, the equilibrium concentration drops too fast with respect to both acidobase reaction probability and diffusion rate of SLC18:0. In this case, supersaturation is high due to the large difference between the amount of soluble lipid, still high, and the actual low $\mathrm{pH}$, which imposes small value of the equilibrium concentration. The high supersaturation decreases the crystallographic mismatch energy barrier and tip and side branching become then possible, thus forming spherulites; the mechanical properties of the gel are reduced or even inexistent, as a powdery precipitate forms. These facts now explain the strong differences in terms of mechanical properties between the hydrogel obtained by GDL hydrolysis and manual addition of $\mathrm{HCl}$ (Figure $\mathrm{S} \mathrm{2}$ ), as well as the difficulty to reproduce a hydrogel when $\mathrm{HCl}$ is added manually. Manual addition using $\mathrm{HCl}$ solutions of typical molarity between $0.1 \mathrm{M}$ and 1 $\mathrm{M}$ is responsible for small, but sensitive, $\mathrm{pH}$ jumps, which can be at the origin of supersaturation phenomena and high degrees of branching. When precipitation due to spherulite formation is not favored over gelling (most common result), the resulting gel is generally weaker between one and two orders of magnitude (Figure 3). Using $\mathrm{HCl}$ solutions of molarity below $0.1 \mathrm{M}$ would on the contrary result in an overall dilution of the initial compound, which would also lead to a weaker gel. In the end, to prepare a reproducible tough hydrogel composed of SLC18:0, slow $(<50 \mathrm{mM} / \mathrm{h}$ ) and continuous addition of $\mathrm{HCl}$ (generally $0.5 \mathrm{M}$ or $1 \mathrm{M}$ is 
acceptable) under stirring ( $\leq 300 \mathrm{rpm}$ ), or appropriate amount of GDL (leaving the solution at rest), should be employed.

\section{Conceptual and practical considerations}

Effect of charge and relevance of final $\mathrm{pH}$. Most of the previous literature work states that the final $\mathrm{pH}$ strongly determines the strength and stability of the gel. This effect could be explained by the neutralization of the negative charges on the fibers. Although side-branching and spherulite formation could not be explained by such an argument, we have tested the effect of $\mathrm{pH}$ on the stability of the gel for the SLC18:0 system. Electrophoretic mobility experiments run from $\mathrm{pH} \sim 11$ to $\mathrm{pH} \sim 2$ (Figure $\mathrm{S} 5 \mathrm{a}$ ) on a diluted solution (0.25 wt\%) of SLC18:0 qualitatively show that negative charges (the exact origin and localization of which are impossible to determine in this qualitative experiment) are persistent to at least $\mathrm{pH} 4$ and become negligible below pH 3, below which one should not expect to obtain a stable gel. In fact, when GDL or controlled addition of $\mathrm{HCl}$ solutions are employed, gels are easily obtained at $\mathrm{pH}$ values as low as 2 and they are stable over an "infinite" period of time. At the same time, spherulite formation, weak gels or precipitation can be observed at $\mathrm{pH}$ between 6 and 7, that is during the nucleation and growth phase and when the system presents negative charges. This is shown on Figure S 5c,d, where the gel formation is followed in-situ as a function of time for a SLC18:0 concentration of $5 \mathrm{wt} \%$ and using large amounts of GDL. In all cases, $G^{\prime} \sim 100 \mathrm{~Pa}$, a value that is two orders of magnitude lower that $G^{\prime}$ recorded on the same sample, prepared with the optimized amount of GDL (Figure S 2b). Figure S 5d even shows the loss of all mechanical properties after about 400 minutes (shrinkage is excluded because the gap is allowed to adjust setting normal force to zero during measurement). The loss of the properties is simply due to sedimentation of the spherulites. Sedimentation can actually be observed visually in the solution. These experiments show that final $\mathrm{pH}$ and surface charge are not involved in spherulite formation and, eventually, precipitation, resulting in the loss of the gel mechanical properties.

Effect of salt. When spherulites form, one should not expect to have strong gels or even no gels at all. However, one can increase the $\mathrm{pH}$ again above 8 and lower it again by changing the rate of addition, or adding GDL, for instance. However, starting from basic $\mathrm{pH}$ values, and multiple $\mathrm{pH}$ changes in general, generate salt ( $\mathrm{NaCl}$ in this work), which may have a deleterious effect on fibrillation, as we have also supposed in a previous work. ${ }^{94}$ In a standard experiment performed for $1 \mathrm{~mL}$ solution and SLC18:0 concentration of $5 \mathrm{wt} \%$, one can typically generate $50 \mathrm{mM}$ of $\mathrm{NaCl}$ or less, according to the initial $\mathrm{pH}$ value. Figure $\mathrm{S} 5 \mathrm{~b} 1$ compares the mechanical properties of two gels prepared under exactly the same conditions (please refer to the 
Supporting Information for more details). One contains about $20 \mathrm{mM} \mathrm{NaCl}$, simply generated by the $\mathrm{pH}$ change process, and the other one has an additional content of $250 \mathrm{mM}$ of $\mathrm{NaCl}$, introduced in the solution at basic $\mathrm{pH}$, before the $\mathrm{pH}$ change process. The system with high salt content has slightly worst mechanical properties $\left(G^{\prime} \sim 150 \mathrm{~Pa}\right.$ against $\left.G^{\prime} \sim 350 \mathrm{~Pa}\right)$ and a larger strain overshoot (Figure S 5b2), suggesting the presence of more spherulitic structures. However, the effect is far from being impressive and one can consider that both gels still have mechanical properties in the same order of magnitude. These data suggest that, if needed, one can regenerate the same gel several times before considering that salt may have an actual effect on the mechanical properties. Although a thorough study of salt effects are out of the scope of this work, our experience shows that gels become difficult to reproduce above at least $0.5 \mathrm{M}$ of $\mathrm{NaCl}$.

GDL against controlled $\mathrm{HCl}$. Our data show that the gel properties strongly depend on the kinetics of acid addition, independently of its nature and final $\mathrm{pH}$. To further support this statement, we have prepared a gel by adding a concentrated solution of gluconic acid to a basic solution of SLC18:0, where gluconic acid is directly prepared from hydrolyzing GDL in water overnight. Figure S 5b1,b2 show that the mechanical properties of two gels (concentration of SLC18:0 is $2.5 \mathrm{wt} \%$, volume is $1 \mathrm{~mL}$ ), respectively prepared by adding a solution of either $\mathrm{HCl}$ or gluconic acid (both at $0.25 \mathrm{M}$ and added at a rate of $20 \mu \mathrm{L} / \mathrm{h}$ ), are comparable, with $G^{\prime}$ ranging between $200 \mathrm{~Pa}$ and $350 \mathrm{~Pa}$. Interestingly, these values are still one order of magnitude smaller with respect to the use of GDL $\left(G^{\prime}>10^{3} \mathrm{~Pa}\right.$ for SLC18:0 at $\left.2.5 \mathrm{wt} \%\right)$. These data show that: 1) the nature of the acid is not an important factor; 2) the use of GDL/gluconic acid does not bring any specific added value to the system, nor it interferes with fibrillation; 3) the rate of GDL hydrolysis, or the rate of addition of gluconic acid, are, again, the main critical parameters to control the gel mechanical properties. Of all the experiments that we have performed, it is clear that use of GDL has systematically provided the strongest gels. However, we stress the fact that GDL can also induce spherulite formation, weak gels and precipitation. In Table 1, we provide the optimum amounts of GDL, that we have found for this system. Lower amounts will not reduce the $\mathrm{pH}$ enough while higher amounts provoke a rapid $\mathrm{pH}$ transition, favouring spherulite formation. Nonetheless, the reader should be aware that these values strongly depend on the initial $\mathrm{pH}$, that is on the amount of base that it is introduced in the system. In fact, reproducibility of gel with GDL may actually be very poor and should systematically be optimized, because the amount of initial base may not be strictly identical from one experiment to another. In addition, hydrolysis rate of GDL is strongly dependent on temperature, which may also limit the reproducibility of a given experiment. These are certainly the main drawbacks of using 
GDL. On the contrary, a controlled addition of $\mathrm{HCl}$ (or gluconic acid) guaranties a direct control of the rate and $\mathrm{pH}$ at all time, thus ensuring a better reproducibility of the experiment, independently on the initial $\mathrm{pH}$ value.

If having a good control of the addition rate of the acid guarantees a more reproducible result from one user to another, gels prepared through GDL still seem to have better mechanical properties. Although GDL hydrolysis is not homogeneous in time, one can qualitatively evaluate an equivalent corresponding acidification rate. For practical reasons, acidification rates throughout this work are reported in $\mu \mathrm{L} / \mathrm{h}$, but using $\mathrm{mM} / \mathrm{h}$ units will help comparing acidifications rates with GDL and $\mathrm{HCl}$. For a typical SLC18:0 concentration of $5 \mathrm{wt} \%$ in $1 \mathrm{~mL}$ at $\mathrm{pH} 11$, we have employed a $50 \mathrm{mM}$ solution of GDL (Table 1). If the experiment is run over $300 \mathrm{~min}$, one can estimate an average hydrolysis rate of $10 \mathrm{mM} / \mathrm{h}$. Interestingly, if the same system is acidified with a $1 \mathrm{M} \mathrm{HCl}$ solution added at $30 \mu \mathrm{L} / \mathrm{h}$ (Figure $3 \mathrm{e}$ ), the rate is $30 \mathrm{mM} / \mathrm{h}$, that is three times faster, resulting in a weaker gel. These considerations reinforce the idea that the hydrolysis rate is the actual key to control the mechanical properties of the gel.

Other factors. It may not be excluded that other factors may play a key role and are worth exploring in the future: 1) constancy of the acidification rate; 2) initial $\mathrm{pH}$; 3) stirring; 4) volumes; 5) nucleation centers. The acidification profiles of GDL and $\mathrm{HCl}$ are not the same in the beginning of the acidification curve (Figure 3a,b). At the moment, it is not clear whether or not the rate of $\mathrm{pH}$ change before fibrillation has any significant impact, nor it is clear whether or not the initial $\mathrm{pH}$ plays a role. According to our experience, good quality gels can be obtained starting when initial $\mathrm{pH}$ is 11 (data in this work) or 9. We have also obtained strong gels both when acidification rate is either constant or not. However, these qualitative results do not mean that these parameters may not have an effect on branching, and consequently on gel strength. Stirring, only employed here upon $\mathrm{HCl}$ acidification, may also have an important effect. We have experienced good gels both under strong $(>500 \mathrm{rpm})$ and mild $(<200 \mathrm{rpm})$ stirring conditions, but it may not be excluded that the better mechanical properties of the GDLacidified systems are related to its steady state. In this case, when employing $\mathrm{HCl}$, one could prefer mild stirring conditions, which, however, may not guarantee satisfactory homogenization. Adapting the size of the stirrer to the volume of the solution may also be an important parameter to explore. Finally, the entire process described in this work is governed by heterogenous nucleation phenomena, whereas the presence of a substrate lowers the energy barrier. It may not be excluded that small heterogeneities may favor spherulite nucleation and growth. Spurious use of ultrasounds can be possible during the nucleation phase to help dissolve the nuclei before lowering the $\mathrm{pH}$. 


\section{Conclusion}

In this work we explore the $\mathrm{pH}$-driven hydrogel properties of stearic acid sophorolipid, a microbial glycolipid. This compound is known to undergo a micelle-to-twisted ribbon phase transition around $\mathrm{pH} 7.4$ and we show here that above $1 \mathrm{wt} \%$ it is possible to form a selfassembled fibrillary network (SAFiN) hydrogel. At a first glance, this system behaves as fluorenyl-9-methoxycarbonyl (Fmoc) amino acid derivatives, which form hydrogels below a given $\mathrm{pH}$. In particular, we show that use of internal acidification using the hydrolysis of glucono- $\delta$-lactone (GDL) provides a homogenous and stronger hydrogel than a more classical manual $\mathrm{pH}$ variation approach using $\mathrm{HCl}$. Oscillatory rheology experiments show that acidification through GDL provides elastic moduli in the range between $10 \mathrm{kPa}$ and $100 \mathrm{kPa}$, while after using $\mathrm{HCl}$ the elastic moduli are rarely higher than $1 \mathrm{kPa}$. These results corroborate the data recorded on other $\mathrm{pH}$-responsive hydrogels prepared using FMOC derivatives. However, the admitted mechanistic behavior in $\mathrm{pH}$-responsive hydrogels is that the final $\mathrm{pH}$ governs the gel mechanical properties, which is not what we find in this work.

In the second part of the paper we demonstrate that mechanical properties of SLC180 hydrogel do not actually depend on the acidification method itself but on the rate of acidification, may it occur through $\mathrm{HCl}$ addition, provided a strict control over the addition of $\mathrm{HCl}$ to the solution, or GDL hydrolysis. In contrast to what is generally known, both $\mathrm{HCl}$ and GDL can induce a phase separation observed through precipitation of spherulites in the solution. If SAXS experiments show that whichever the method of preparation, SLC18:0 always nucleates into self-assembled fibers below neutral $\mathrm{pH}$, cryo-TEM and optical microscopy experiments allow to associate side branching and spherulite formation of fast $\mathrm{HCl}$ acidification rates or excess of GDL. Rheology shows, on the contrary, that hydrogels with similar mechanical properties can be prepared with low $\mathrm{HCl}$ acidification rates or optimal GDL amount. Solution NMR spectroscopy performed on two systems, one containing excess (leading to precipitation) and the other an optimal amount (leading to gel) of GDL, reveals an important mismatch between the expected equilibrium and measured SLC18:0 concentrations as a function of $\mathrm{pH}$ when excess of GDL is employed. This experiment proves the existence of supersaturation when $\mathrm{pH}$ changes too fast. Supersaturation is known to decrease the crystallographic mismatch nucleation energy, a necessary and sufficient condition to observe side branching and spherulite formation in SAFiN prepared with low molecular weight gelators. In clear, slow acidification rates promote strong SLC18:0 hydrogels with low, or no, degree of branching, while high acidification rates promote highly branched fibers forming weak gels, or 
no gels at all. Although the origin of this phenomenon is still not clear, we think that the micellar environment in the $\mathrm{pH}$ region prior to nucleation and growth of the fibers establishes a limited process, slowing down the SLC18:0 molecular diffusion from the micelles to the nucleating fibers. Additional experiments are needed to better understand this phenomenon.

\section{Acknowledgements}

Research leading to these results received funding from the European Community's Seventh Framework Programme (FP7/2007-2013) under Grant Agreement No. Biosurfing/289219. This work also received financial support by the European Synchrotron Radiation Facility (ESRF), Grenoble, France, under the experiment number SC 4778. Mr. Abdoul Aziz Ba (Sorbonne Université, Paris, France) and Mrs Chloé Seyrig (Sorbonne Université, Paris, France) are acknowledged for their experimental assistance. Dr. Thibaut Divoux (CNRS, MIT) is acknowledged for helpful discussion on rheology.

Supporting Information. Figure S 1 illustrates the typical setup employed for controlled acidification. Figure S 2 shows the rheological properties of SLC18:0 hydrogels. Figure S 3 shows Small Angle X-ray Scattering experiments. Figure S 4 reports the kinetic experiments (mmicelles molar fration, FWHM and Avrami plots) performed through 1H solution NMR. Figure S 5 combines electrophoretic mobility experiments and complementary rheology analyses. This material is available free of charge via the internet at http://pubs.acs.org 


\section{References}

(1) Okesola, B. O.; Smith, D. K. Applying Low-Molecular Weight Supramolecular Gelators in an Environmental Setting-Self-Assembled Gels as Smart Materials for Pollutant Removal. Chem. Soc. Rev. 2016, 45, 4226-4251.

(2) Colquhoun, C.; Draper, E. R.; Schweins, R.; Marcello, M.; Vadukul, D.; Serpell, L. C.; Adams, D. J. Controlling the Network Type in Self-Assembled Dipeptide Hydrogels. Soft Matter 2017, 13, 1914-1919.

(3) Venkatesh, V.; Mishra, N. K.; Romero-Canelón, I.; Vernooij, R. R.; Shi, H.; Coverdale, J. P. C.; Habtemariam, A.; Verma, S.; Sadler, P. J. Supramolecular Photoactivatable Anticancer Hydrogels. J. Am. Chem. Soc. 2017, 139, 5656-5659.

(4) Ramin, M. A.; Latxague, L.; Sindhu, K. R.; Chassande, O.; Barthélémy, P. Low Molecular Weight Hydrogels Derived from Urea Based-Bolaamphiphiles as New Injectable Biomaterials. Biomaterials 2017, 145, 72-80.

(5) Huang, G.; Li, F.; Zhao, X.; Ma, Y.; Li, Y.; Lin, M.; Jin, G.; Lu, T. J.; Genin, G. M.; $\mathrm{Xu}, \mathrm{F}$. Functional and Biomimetic Materials for Engineering of the Three-Dimensional Cell Microenvironment. Chem. Rev. 2017, 117, 12764-12850.

(6) Nolan, M. C.; Fuentes Caparrós, A. M.; Dietrich, B.; Barrow, M.; Cross, E. R.; Bleuel, M.; King, S. M.; Adams, D. J. Optimising Low Molecular Weight Hydrogels for Automated 3D Printing. Soft Matter 2017, 13, 8426-8432.

(7) Frith, W. J. Self-Assembly of Small Peptide Amphiphiles, the Structures Formed and Their Applications. (a Foods and Home and Personal Care Perspective). Philos. Trans. R. Soc. A Math. Phys. Eng. Sci. 2016, 374, 20150138.

(8) Stubenrauch, C.; Gießelmann, F. Gelled Complex Fluids: Combining Unique Structures with Mechanical Stability. Angew. Chemie - Int. Ed. 2016, 55, 3268-3275.

(9) Sydney Gladman, A.; Matsumoto, E. A.; Nuzzo, R. G.; Mahadevan, L.; Lewis, J. A. Biomimetic 4D Printing. Nat. Mater. 2016, 15, 413-418.

(10) Draper, E. R.; Adams, D. J. Low-Molecular-Weight Gels: The State of the Art. Chem 2017, 3, 390-410.

(11) Du, X.; Zhou, J.; Shi, J.; Xu, B. Supramolecular Hydrogelators and Hydrogels: From Soft Matter to Molecular Biomaterials. Chem. Rev. 2015, 115, 13165-13307.

(12) Qiao, Y.; Lin, Y.; Yang, Z.; Chen, H.; Zhang, S.; Yan, Y.; Huang, J. Unique Temperature-Dependent Supramolecular Self-Assembly: From Hierarchical 1D Nanostructures to Super Hydrogel. J. Phys. Chem. B 2010, 114, 11725-11730.

(13) Jayawarna, V.; Ali, M.; Jowitt, T. A.; Miller, A. F.; Saiani, A.; Gough, J. E.; Ulijn, R. 
V. Nanostructured Hydrogels for Three-Dimensional Cell Culture Through SelfAssembly of Fluorenylmethoxycarbonyl-Dipeptides. Adv. Mater. 2006, 18, 611-614.

(14) Ozbas, B.; Kretsinger, J.; Rajagopal, K.; Schneider, J. P.; Pochan, D. J. Salt-Triggered Peptide Folding and Consequent Self-Assembly into Hydrogels with Tunable Modulus. Macromolecules 2004, 37, 7331-7337.

(15) He, H.; Wang, H.; Zhou, N.; Yang, D.; Xu, B. Branched Peptides for Enzymatic Supramolecular Hydrogelation. Chem. Commun. 2018, 54, 86-89.

(16) Raeburn, J.; Cardoso, A. Z.; Adams, D. J. The Importance of the Self-Assembly Process to Control Mechanical Properties of Low Molecular Weight Hydrogels. Chem. Soc. Rev. 2013, 42, 5143-5156.

(17) Jung, J. H.; Rim, J. A.; Han, W. S.; Lee, S. J.; Lee, Y. J.; Cho, E. J.; Kim, J. S.; Ji, Q.; Shimizu, T. Hydrogel Behavior of a Sugar-Based Gelator by Introduction of an Unsaturated Moiety as a Hydrophobic Group. Org. Biomol. Chem. 2006, 4, $2033-$ 2038.

(18) Greenfield, M. A.; Hoffman, J. R.; De La Cruz, M. O.; Stupp, S. I. Tunable Mechanics of Peptide Nanofiber Gels. Langmuir 2010, 26, 3641-3647.

(19) Clemente, M. J.; Fitremann, J.; Mauzac, M.; Serrano, J. L.; Oriol, L. Synthesis and Characterization of Maltose-Based Amphiphiles as Supramolecular Hydrogelators. Langmuir 2011, 27, 15236-15247.

(20) Jung, J. H.; John, G.; Masuda, M.; Yoshida, K.; Shinkai, S.; Shimizu, T. Self-Assembly of a Sugar-Based Gelator in Water: Its Remarkable Diversity in Gelation Ability and Aggregate Structure. Langmuir 2001, 17, 7229-7232.

(21) Liu, X. Y.; Sawant, P. D. Mechanism of the Formation of Self-Organized Microstructures in Soft Functional Materials. Adv. Mater. 2002, 14, 421-426.

(22) Liu, X. Y.; Sawant, P. D. Formation Kinetics of Fractal Nanofiber Networks in Organogels. Appl. Phys. Lett. 2001, 79, 3518-3520.

(23) Wang, R.; Liu, X.-Y.; Xiong, J.; Li, J. Real-Time Observation of Fiber Network Formation in Molecular Organel: Supersaturation-Dependent Microstructure and Its Related Rheological Property. J. Phys. Chem. B. 2006, 110, 7275.

(24) Yu, R.; Lin, N.; Yu, W.; Liu, X. Y. Crystal Networks in Supramolecular Gels: Formation Kinetics and Mesoscopic Engineering Principles. CrystEngComm 2015, 17, 7986-8010.

(25) Draper, E. R.; Mears, L. L. E.; Castilla, A. M.; King, S. M.; McDonald, T. O.; Akhtar, R.; Adams, D. J. Using the Hydrolysis of Anhydrides to Control Gel Properties and 
Homogeneity in PH-Triggered Gelation. RSC Adv. 2015, 5, 95369-95378.

(26) Raeburn, J.; McDonald, T. O.; Adams, D. J. Dipeptide Hydrogelation Triggered via Ultraviolet Light. Chem. Commun. 2012, 48, 9355-9357.

(27) Adams, D. J.; Butler, M. F.; Frith, W. J.; Kirkland, M.; Mullen, L.; Sanderson, P. A New Method for Maintaining Homogeneity during Liquid-Hydrogel Transitions Using Low Molecular Weight Hydrogelators. Soft Matter 2009, 5, 1856-1862.

(28) Wang, H.; Yang, Z.; Adams, D. J. Controlling Peptide-Based Hydrogelation. Mater. Today 2012, 15, 500-507.

(29) Helen, W.; De Leonardis, P.; Ulijn, R. V.; Gough, J.; Tirelli, N. Mechanosensitive Peptide Gelation: Mode of Agitation Controls Mechanical Properties and Nano-Scale Morphology. Soft Matter 2011, 7, 1732-1740.

(30) Johnson, E. K.; Adams, D. J.; Cameron, P. J. Directed Self-Assembly of Dipeptides to Form Ultrathin Hydrogel Membranes. J. Am. Chem. Soc. 2010, 132, 5130-5136.

(31) Chen, L.; Morris, K.; Laybourn, A.; Elias, D.; Hicks, M. R.; Rodger, A.; Serpell, L.; Adams, D. J. Self-Assembly Mechanism for a Naphthalene-Dipeptide Leading to Hydrogelation. Langmuir 2010, 26, 5232-5242.

(32) Cuvier, A. S.; Berton, J.; Stevens, C. V; Fadda, G. C.; Babonneau, F.; Van Bogaert, I. N. A.; Soetaert, W.; Pehau-Arnaudet, G.; Baccile, N. PH-Triggered Formation of Nanoribbons from Yeast-Derived Glycolipid Biosurfactants. Soft Matter 2014, 10, 3950-3959.

(33) Van Bogaert, I. N. A.; Saerens, K.; De Muynck, C.; Develter, D.; Soetaert, W.; Vandamme, E. J. Microbial Production and Application of Sophorolipids. Appl. Microbiol. Biotechnol. 2007, 76, 23-34.

(34) Marchant, R.; Banat, I. M. Microbial Biosurfactants: Challenges and Opportunities for Future Exploitation. Trends Biotechnol. 2012, 30, 558-565.

(35) Dhasaiyan, P.; Banerjee, A.; Visaveliya, N.; Prasad, B. L. V. Influence of the Sophorolipid Molecular Geometry on Their Self-Assembled Structures. Chem. Asian J. 2013, 8, 369-372.

(36) Dhasaiyan, P.; Prasad, B. L. V. Self-Assembly of Bolaamphiphilic Molecules. Chem. Rec. 2017, 17, 597-610.

(37) Zhou, S.; Xu, C.; Wang, J.; Gao, W.; Akhverdiyeva, R.; Shah, V.; Gross, R. Supramolecular Assemblies of a Naturally Derived Sophorolipid. Langmuir 2004, 20 , 7926-7932.

(38) Roelants, S. L. K. W.; Renterghem, L. Van; Maes, K.; Everaert, B.; Redant, E.; 
Vanlerberghe, B.; Demaeseneire, S.; Soetaert, W. Taking Biosurfactants from the Lab to the Market: Hurdles and How to Take Them by Applying an Integrated Process Design Approach. In Microbial Biosurfactants and their Environmental and Industrial Applications; Banat, I. M., Thavasi, R., Eds.; CRC Press, 2018.

(39) Imura, T.; Kawamura, D.; Ishibashi, Y.; Morita, T.; Sato, S.; Fukuoka, T.; Kikkawa, Y.; Kitamoto, D. Low Molecular Weight Gelators Based on Biosurfactants, Cellobiose Lipids by Cryptococcus Humicola. J. Oleo Sci. 2012, 61, 659-664.

(40) Imura, T.; Yamamoto, S.; Yamashita, C.; Taira, T.; Minamikawa, H.; Morita, T.; Kitamoto, D. Aqueous Gel Formation from Sodium Salts of Cellobiose Lipids. J. Oleo Sci. 2014, 63, 1005-1010.

(41) Baccile, N.; Renterghem, L. Van; Griel, P. Le; Ducouret, G.; Brennich, M.; Cristiglio, V.; Roelants, S. L. K. W.; Soetaert, W. Bio-Based Glyco-Bolaamphiphile Forms a Temperature-Responsive Hydrogel with Tunable Elastic Properties. Soft Matter 2018, $14,7859-7872$.

(42) Wang, R. Y.; Liu, X. Y.; Narayanan, J.; Xiong, J. Y.; Li, J. L. Architecture of Fiber Network: From Understanding to Engineering of Molecular Gels. J. Phys. Chem. B 2006, 110, 25797-25802.

(43) Liu, X. Y. Gelation with Small Molecules: From Formation Mechanism to NanostructureArchitecture. Top. Curr. Chem. 2005, 256, 1-37.

(44) Wang, R.; Liu, X.-Y.; Xiong, J.; Li, J. Real-Time Observation of Fiber Network Formation in Molecular Organel: Supersaturation-Dependent Microstructure and Its Related Rheological Property. J. Phys. Chem. B. 2006, 110, 7275.

(45) Baccile, N.; Cuvier, A.-S.; Valotteau, C.; Van Bogaert, I. N. A. Practical Methods to Reduce Impurities for Gram-Scale Amounts of Acidic Sophorolipid Biosurfactants. Eur. J. Lipid Sci. Technol. 2013, 115, 1404-1412.

(46) Cuvier, A. S.; Babonneau, F.; Berton, J.; Stevens, C. V.; Fadda, G. C.; PéhauArnaudet, G.; Le Griel, P.; Prévost, S.; Perez, J.; Baccile, N. Nanoscale Platelet Formation by Monounsaturated and Saturated Sophorolipids under Basic PH Conditions. Chem. - A Eur. J. 2015, 21, 19265-19277.

(47) Bras, W.; Dolbnya, I. P.; Detollenaere, D.; van Tol, R.; Malfois, M.; Greaves, G. N.; Ryan, A. J.; Heeley, E. Recent Experiments on a Small-Angle/Wide-Angle X-Ray Scattering Beam Line at the ESRF. J. Appl. Crystallogr. 2003, 36, 791-794.

(48) Portale, G.; Cavallo, D.; Alfonso, G. C.; Hermida-Merino, D.; van Drongelen, M.; Balzano, L.; Peters, G. W. M.; Goossens, J. G. P.; Bras, W. Polymer Crystallization 
Studies under Processing-Relevant Conditions at the SAXS/WAXS DUBBLE Beamline at the ESRF. J. Appl. Crystallogr. 2013, 46, 1681-1689.

(49) Wallace, M.; Iggo, J. A.; Adams, D. J. Using Solution State NMR Spectroscopy to Probe NMR Invisible Gelators. Soft Matter 2015, 11, 7739-7747.

(50) Fuhrhop, J. H.; Svenson, S.; Boettcher, C.; Rössler, E.; Vieth, H. M. Long-Lived Micellar N-Alkylaldonamide Fiber Gels. Solid-State NMR and Electron Microscopic Studies. J. Am. Chem. Soc. 1990, 112, 4307-4312.

(51) Frkanec, L.; Jokić, M.; Makarević, J.; Wolsperger, K.; Žinić, M. Bis(PheOH) Maleic Acid Amide-Fumaric Acid Amide Photoizomerization Induces Microsphere-to-Gel Fiber Morphological Transition: The Photoinduced Gelation System. J. Am. Chem. Soc. 2002, 124, 9716-9717.

(52) http://nmr.cemhti.cnrs-orleans.fr/dmfit. DMFit http://nmr.cemhti.cnrs-orleans.fr/dmfit.

(53) Massiot, D.; Fayon, F.; Capron, M.; King, I.; Calvé, S. Le; Alonso, B.; Durand, J. O.; Bujoli, B.; Gan, Z.; Hoatson, G. Modelling One and Two-Dimensional Solid-State NMR Spectra. Magn. Reson. Chem. 2002, 40, 70-76.

(54) Avrami, M. Kinetics of Phase Change. I General Theory. J. Chem. Phys. 1939, 7, 1103-1112.

(55) Avrami, M. Granulation, Phase Change, and Microstructure Kinetics of Phase Change. III. J. Chem. Phys. 1941, 9, 177-184.

(56) Terech, P. Kinetics of Aggregation in a Steroid Derivative/Cyclohexane Gelifying System. J. Colloid Interface Sci. 1985, 107, 244-255.

(57) Lopes-da-Silva, J. A.; Coutinho, J. A. P. Analysis of the Isothermal Structure Development in Waxy Crude Oils under Quiescent Conditions. Energy and Fuels 2007, 21, 3612-3617.

(58) Feio, G.; Cohen-Addad, J. P. NMR Approach to the Kinetics of Polymer Crystallization. 1. Cis-1,4-Polybutadiene. J. Polym. Sci. Part B Polym. Phys. 1988, 26, $389-412$.

(59) Baccile, N.; Cuvier, A. S.; Prévost, S.; Stevens, C. V.; Delbeke, E.; Berton, J.; Soetaert, W.; Van Bogaert, I. N. A.; Roelants, S. Self-Assembly Mechanism of PH-Responsive Glycolipids: Micelles, Fibers, Vesicles, and Bilayers. Langmuir 2016, 32, 1088110894.

(60) Tang, C.; Smith, A. M.; Collins, R. F.; Ulijn, R. V.; Saiani, A. Fmoc-Diphenylalanine Self-ASsembly Mechanism Induces Apparent PKaShifts. Langmuir 2009, 25, 94479453. 
(61) Tang, C.; Ulijn, R. V.; Saiani, A. Effect of Glycine Substitution on FmocDiphenylalanine Self-Assembly and Gelation Properties. Langmuir 2011, 27, 1443814449.

(62) Kierfeld, J.; Baczynski, K.; Gutjahr, P.; Lipowsky, R. Semiflexible Polymers and Filaments: From Variational Problems to Fluctuations; 2008; Vol. 1002.

(63) de Gennes, P.-G. Dynamics of Entangled Polymer Solutions. I. The Rouse Model. Macromolecules 1976, 9, 587-593.

(64) de Rooij, R.; van den Ende, D.; Duits, M. H. G.; Mellema, J. Elasticity of Weakly Aggregating Polystyrene Latex Dispersions. Phys. Rev. E 1994, 49, 3038-3049.

(65) Flory, P. J. Principles of Polymer Chemistry; Cornell University Press: Ithaca, NY, NY, 1953.

(66) MacKintosh, F. C.; Käs, J.; Janmey, P. A. Elasticity of Semiflexible Biopolymer Networks. Phys. Rev. Lett. 1995, 75, 4425-4428.

(67) Chen, S. Q.; Lopez-Sanchez, P.; Wang, D.; Mikkelsen, D.; Gidley, M. J. Mechanical Properties of Bacterial Cellulose Synthesised by Diverse Strains of the Genus Komagataeibacter. Food Hydrocoll. 2018, 81, 87-95.

(68) Hyun, K.; Wilhelm, M.; Klein, C. O.; Cho, K. S.; Nam, J. G.; Ahn, K. H.; Lee, S. J.; Ewoldt, R. H.; McKinley, G. H. A Review of Nonlinear Oscillatory Shear Tests: Analysis and Application of Large Amplitude Oscillatory Shear (LAOS). Prog. Polym. Sci. 2011, 36, 1697-1753.

(69) Mason, T. G.; Bibette, J.; Weitz, D. A. Elasticity of Compressed Emulsions. Phys. Rev. Lett. 1995, 75, 2051.

(70) Cloitre, M.; Borrega, R.; Leibler, L. Rheological Aging and Rejuvenation in Microgel Pastes. Phys. Rev. Lett. 2000, 85, 4819.

(71) O’Leary, L. E. R.; Fallas, J. A.; Bakota, E. L.; Kang, M. K.; Hartgerink, J. D. MultiHierarchical Self-Assembly of a Collagen Mimetic Peptide from Triple Helix to Nanofibre and Hydrogel. Nat. Chem. 2011, 3, 821-828.

(72) Tirtaatmadja, V.; Ta, K. C.; Jenkins, R. D. Rheological Properties of Model AlkaliSoluble Associative (HASE) Polymers: Effect of Varying Hydrophobe Chain Length. Macromolecules 1997, 30, 3271-3282.

(73) Raghavan, S. R.; Khan, S. A. Shear-induced Microstructural Changes in Flocculated Suspensions of Fumed Silica. J. Rheol. (N. Y. N. Y). 1995, 39, 1311.

(74) Parthasarathy, M.; Klingenberg, D. J. Large Amplitude Oscillatory Shear of ER Suspensions. J. Nonnewton. Fluid Mech. 1999, 81, 83-104. 
(75) Dudukovic, N. A.; Zukoski, C. F. Mechanical Properties of Self-Assembled FmocDiphenylalanine Molecular Gels. Langmuir 2014, 30, 4493-4500.

(76) Menger, F. M.; Caran, K. L. Anatomy of a Gel. Amino Acid Derivatives That Rigidify Water at Submillimolar Concentrations. J. Am. Chem. Soc. 2000, 122, 11679-11691.

(77) Komatsu, H.; Ikeda, M.; Hamachi, I. Mechanical Reinforcement of Supramolecular Hydrogel through Incorporation of Multiple Noncovalent Interactions. Chem. Lett. 2011, 40, 198-200.

(78) Clemente, M. J.; Fitremann, J.; Mauzac, M.; Serrano, J. L.; Oriol, L. Synthesis and Characterization of Maltose-Based Amphiphiles as Supramolecular Hydrogelators. Langmuir 2011, 27, 15236-15247.

(79) Clemente, J.; Romero, P.; Serrano, J. L.; Fitremann, J.; Oriol, L. Supramolecular Hydrogels Based on Glycoamphiphiles: E Ff Ect of the Disaccharide Polar Head. 2012, No. Lc.

(80) Jung, J. H.; Rim, J. A.; Han, W. S.; Lee, S. J.; Lee, Y. J.; Cho, E. J.; Kim, J. S.; Ji, Q.; Shimizu, T. Hydrogel Behavior of a Sugar-Based Gelator by Introduction of an Unsaturated Moiety as a Hydrophobic Group. Org. Biomol. Chem. 2006, 4, 20332038.

(81) Adams, D. J.; Mullen, L. M.; Berta, M.; Chen, L.; Frith, W. J. Relationship between Molecular Structure, Gelation Behaviour and Gel Properties of Fmoc-Dipeptides. Soft Matter 2010, 6, 1971-1980.

(82) Aufderhorst-Roberts, A.; Frith, W. J.; Donald, A. M. Micro-Scale Kinetics and Heterogeneity of a PH Triggered Hydrogel. Soft Matter 2012, 8, 5940-5946.

(83) Goddard, E. D. Ionizing Monolayers and PH Effects. Adv. Coll. Interf. Sci. 1974, 4 , $45-78$.

(84) Ptak, M.; Egret-Charlier, M.; Sanson, A.; Bouloussa, O. A NMR Study of the Ionization of Fatty Acids, Fatty Amines and N-Acylamino Acids Incorporated in Phosphatidylcholine Vesicles. Biochim. Biophys. Acta - Biomembr. 1980, 600, $387-$ 397.

(85) Cistola, D. P.; Hamilton, J. A.; Jackson, D.; Small, D. M. Ionization and PhaseBehavior of Fatty-Acids in Water - Application of the Gibbs Phase Rule. Biochemistry 1988, 27, 1881-1888.

(86) Aufderhorst-Roberts, A.; Frith, W. J.; Kirkland, M.; Donald, A. M. Microrheology and Microstructure of Fmoc-Derivative Hydrogels. Langmuir 2014, 30, 4483-4492.

(87) Cuvier, A. S.; Babonneau, F.; Berton, J.; Stevens, C. V.; Fadda, G. C.; Genois, I.; Le 
Griel, P.; Péhau-Arnaudet, G.; Baccile, N. Synthesis of Uniform, Monodisperse, Sophorolipid Twisted Ribbons. Chem. - An Asian J. 2015, 10, 2419-2426.

(88) Raeburn, J.; Pont, G.; Chen, L.; Cesbron, Y.; Lévy, R.; Adams, D. J. FmocDiphenylalanine Hydrogels: Understanding the Variability in Reported Mechanical Properties. Soft Matter 2012, 8, 1168-1174.

(89) Baccile, N.; Selmane, M.; Le Griel, P.; Prévost, S.; Perez, J.; Stevens, C. V.; Delbeke, E.; Zibek, S.; Guenther, M.; Soetaert, W.; et al. PH-Driven Self-Assembly of Acidic Microbial Glycolipids. Langmuir 2016, 32, 6343-6359.

(90) Bunton, C. A. Reactions in Micelles and Similar Self-Organized Aggregates, New Compre.; Page, M. I., Ed.; Elsevier: Amsterdam - New York - Oxford, 1984; Vol. 6.

(91) Manet, S.; Cuvier, A. S.; Valotteau, C.; Fadda, G. C.; Perez, J.; Karakas, E.; Abel, S.; Baccile, N. Structure of Bolaamphiphile Sophorolipid Micelles Characterized with SAXS, SANS, and MD Simulations. J. Phys. Chem. B 2015, 119, 13113-13133.

(92) Huang, X.; Terech, P.; Raghavan, S. R.; Weiss, R. G. Kinetics of 5 $\alpha$-Cholestan-3 $\beta$-Y1 $\mathrm{N}$-(2-Naphthyl)Carbamate/n-Alkane Organogel Formation and Its Influence on the Fibrillar Networks. J. Am. Chem. Soc. 2005, 127, 4336-4344.

(93) Toro-Vazquez, J. F.; Dibildox-Alvarado, E.; Charó-Alonso, M.; Herrera-Coronado, V.; Gómez-Aldapa, C. a. The Avrami Index and the Fractal Dimension in Vegetable Oil Crystallization. J. Am. Oil Chem. Soc. 2002, 79, 855-866.

(94) Cuvier, A. S.; Babonneau, F.; Berton, J.; Stevens, C. V.; Fadda, G. C.; Genois, I.; Le Griel, P.; Péhau-Arnaudet, G.; Baccile, N. Synthesis of Uniform, Monodisperse, Sophorolipid Twisted Ribbons. Chem. - An Asian J. 2015, 10, 2419-2426. 
1087

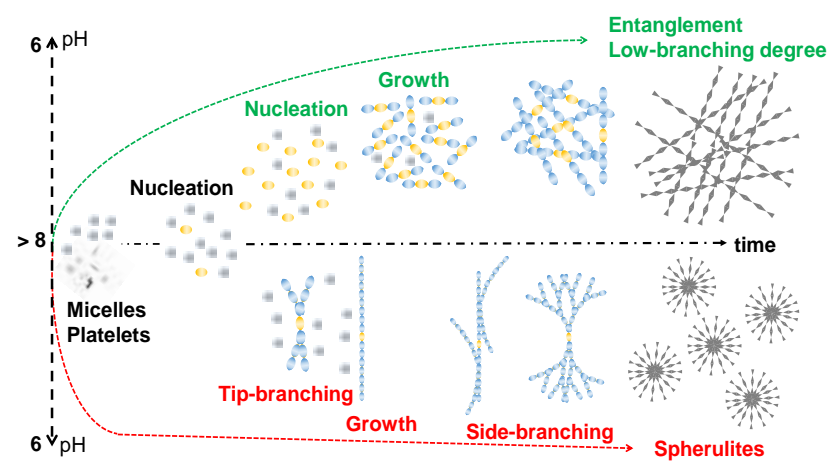

